\title{
A Method for Determination of One Hundred Endogenous Steroids in Human Serum by Gas Chromatography-Tandem Mass Spectrometry
}

\author{
M. HILL ${ }^{1}$, V. HÁNA Jr. ${ }^{2}$, M. VELÍKOVÁ ${ }^{1}$, A. PAŘÍZEK ${ }^{3}$, L. KOLÁTOROVÁ ${ }^{1}, J$. VÍTKŮ ${ }^{1}$, \\ T. ŠKODOVÁ ${ }^{1}$, M. ŠIMKOVÁ ${ }^{1}$, P. ŠIMJÁK ${ }^{3}$, R. KANCHEVA ${ }^{1}$, M. KOUCKÝ ${ }^{3}$, \\ Z. KOKRDOVÁ ${ }^{3}$, K. ADAMCOVÁ ${ }^{3}$, A. ČERNÝ ${ }^{3}$, Z. HÁJEK ${ }^{3}$, M. DUŠKOVÁ ${ }^{1}$, \\ J. BULANT ${ }^{1,4,5}$, L. STÁRKA ${ }^{1}$
}

${ }^{1}$ Department of Steroid Hormones and Proteohormones, Institute of Endocrinology, Prague, Czech Republic, ${ }^{2}$ Third Internal Clinic - Clinic of Endocrinology and Metabolism, General University Hospital and First Faculty of Medicine, Charles University, Prague, Czech Republic, ${ }^{3}$ Department of Gynecology and Obstetrics, General University Hospital and First Faculty of Medicine, Charles University, Prague, Czech Republic, ${ }^{4}$ Department of Psychiatry, First Faculty of Medicine, Charles University and General University Hospital in Prague, Prague, Czech Republic, ${ }^{5}$ Department of Pediatrics and Adolescent Medicine, First Faculty of Medicine, Charles University and General University Hospital in Prague, Prague, Czech Republic

Received January 4, 2019

Accepted January 24, 2019

\section{Summary}

Steroid profiling helps various pathologies to be rapidly diagnosed. Results from analyses investigating steroidogenic pathways may be used as a tool for uncovering pathology causations and proposals of new therapeutic approaches. The purpose of this study was to address still underutilized application of the advanced GC-MS/MS platform for the multicomponent quantification of endogenous steroids. We developed and validated a GC-MS/MS method for the quantification of 58 unconjugated steroids and 42 polar conjugates of steroids (after hydrolysis) in human blood. The present method was validated not only for blood of men and non-pregnant women but also for blood of pregnant women and for mixed umbilical cord blood. The spectrum of analytes includes common hormones operating via nuclear receptors as well as other bioactive substances like immunomodulatory and neuroactive steroids. Our present results are comparable with those from our previously published GC-MS method as well as the results of others. The present method was extended for corticoids and $17 a$-hydroxylated $5 a / \beta$-reduced pregnanes, which are useful for the investigation of alternative "backdoor" pathway. When comparing the analytical characteristics of the present and previous method, the first exhibit by far higher selectivity, and generally higher sensitivity and better precision particularly for 17a-hydroxysteroids.

\section{Key words}

Steroid metabolome - Human blood • Gas chromatographytandem mass spectrometry • Backdoor pathway • Pregnancy • Mixed umbilical cord blood

\section{Corresponding author}

M. Hill, Department of Steroid Hormones and Proteohormones, Institute of Endocrinology, Národní 8, 116 94, Prague, Czech Republic. E-mail: mhill@endo.cz

\section{Introduction}

For almost six decades, gas chromatographymass spectrometry (GC-MS) served as an efficient tool for the routine quantification of endogenous steroids (Hill et al. 2010a, Hill et al. 2010b, Krone et al. 2010). At present, liquid chromatography-tandem mass spectrometry (LC-MS/MS) is also widely used and has become the gold standard for steroid quantification (Soldin and Soldin 2009). A number of LC-MS/MS based steroidomics studies was primarily focused on 
corticosteroids and their metabolites (Gomes et al. 2009, Haneef et al. 2013, Marcos et al. 2014). Other chromatographic strategies may involve a direct LC-MS/MS detection of unaltered glucuronoconjugated metabolites (Esquivel et al. 2017) or the use of supercritical fluids for extraction of steroidome (Kureckova et al. 2002). However, in steroid metabolomics (steroidomics), GC-MS remains the method of choice (Krone et al. 2010). A more advanced and therefore more sensitive, specific and precise GC-MS platform known as gas-chromatography tandem-mass spectrometry (GC-MS/MS) has lately been developed. The GC-MS/MS platform on the one hand retains the advantages of GC-MS in precisely distinguishing isomers with the same mass to charge ratio $(\mathrm{m} / \mathrm{z})$. However, the use of GC-MS/MS in the analysis of endogenous steroids has still been limited. Current studies using the GC-MS/MS platform have mostly focused on the quantification of anabolic steroids in the blood of athletes or farmyard animals (Gambelunghe et al. 2007, Impens et al. 2007, Marcos et al. 2002, Raro et al. 2016, Rossi et al. 1994, Shen et al. 2008, Van Vyncht et al. 1994, Wong et al. 2017, Yamada et al. 2008) or on steroid quantifications in wastewaters (Andrasi et al. 2013, Kelly 2000, Trinh et al. 2011, Zuehlke et al. 2005). Blokland et al. (2012) simultaneously quantified 47 steroids in the form of unconjugated steroids, glucuronides and sulfates in bovine urine. Regarding the number of steroids detected, the lead is still held by a series of studies from Christakoudi and coworkers who identified and quantified human urinary steroids. Their first study included 146 C21 steroids (Christakoudi et al. 2010), the second one 32 additional C21 steroids (Christakoudi et al. 2012a), the third $76 \mathrm{C} 19$ steroids (Christakoudi et al. 2012b) and the fourth study additional 52 C21 steroids (Christakoudi et al. 2013). These studies have provided a complex qualitative picture of the urinary steroid metabolome in humans; however, the lack of validation of the methods used remains its weakness. The authors from research group headed by Man-Ho Choi (Molecular Recognition Research Center of Korea Institute of Science and Technology) published a series of extensive metabolomic studies on the GC-MS platform, which were focused on the role of urinary steroids in human physiology and pathophysiology (Ha et al. 2009, Choi and Chung 2014, Kim et al. 2013, Moon et al. 2016, Moon et al. 2009). There are few GC-MS/MS studies focused on circulating steroids in humans and other mammals, and all have quantified a limited number of steroids (Courant et al. 2010, Hansen et al. 2011, Matysik and Schmitz 2015, Nilsson et al. 2015, Styrishave et al. 2017).

The purpose of this study was to address the application of the GC-MS/MS platform for the simultaneous quantification of endogenous steroids. We developed and validated a GC-MS/MS method for the multicomponent quantification of unconjugated steroids and their polar conjugates (after hydrolysis). Of the original 120 steroids or their polar conjugates tested, only 100 of them met validation criteria for at least some physiological situations. Our method was validated not only for blood of men and non-pregnant women but also for blood of pregnant women and for umbilical cord blood. The spectrum of analytes in our method includes precursor steroids, active steroids and steroid metabolites, and covers the vast part of steroid metabolome in humans (Figs 1 and 2). Steroid profiling helps various pathologies to be rapidly diagnosed. Moreover, the results from analyses investigating steroidogenic pathways may be used as a tool for uncovering pathology causations and proposals of new therapeutic approaches (Bicikova et al. 2013, Hill et al. 2010c, Kanceva et al. 2015, Parizek et al. 2016, Sosvorova et al. 2015, Sterzl et al. 2017, Vankova et al. 2016).

\section{Methods}

\section{Samples}

Serum samples from non-pregnant subjects were collected from the employees of the Institute of Endocrinology, Prague, Czech Republic and their relatives, as well as from patients of the Institute of Endocrinology. Serum samples from pregnant women and umbilical cord serum at birth were obtained from patients of the Department of Gynecology and Obstetrics, General University Hospital and $1^{\text {st }}$ Faculty of Medicine of Charles University in Prague. For all participants, the clinical protocol was approved by the Ethics Committee of the Institute of Endocrinology and by the Ethics Committee of the General University Hospital and $1^{\text {st }}$ Faculty of Medicine of Charles University in Prague. Informed written consent was obtained from all participants. Serum from blood was obtained after centrifugation $\left(5 \mathrm{~min}\right.$ at $2,000 \times \mathrm{g}$ at $\left.2{ }^{\circ} \mathrm{C}\right)$, and stored at $-20^{\circ} \mathrm{C}$ until analyzed. 

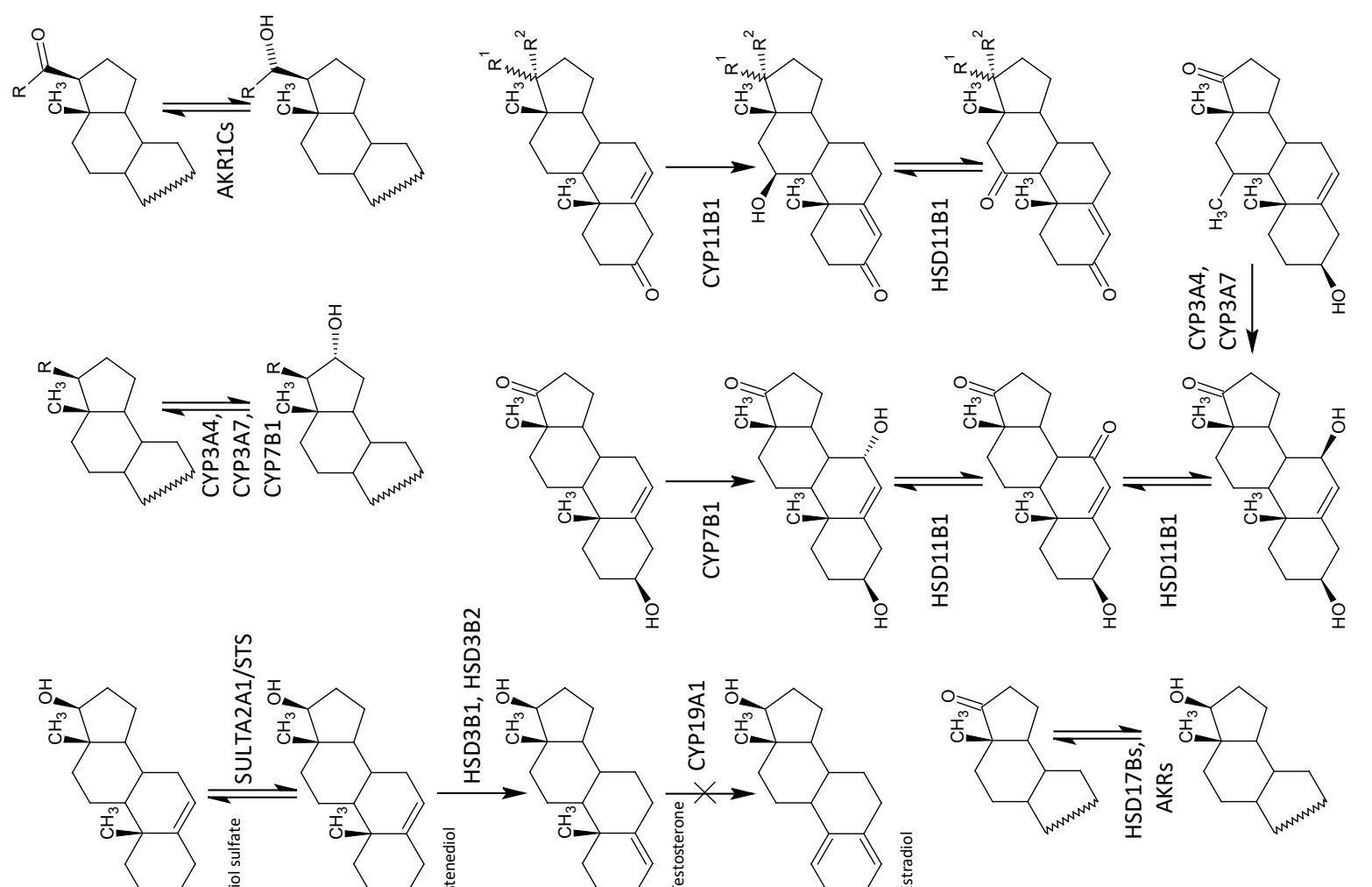

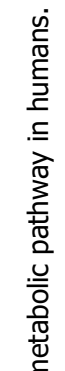

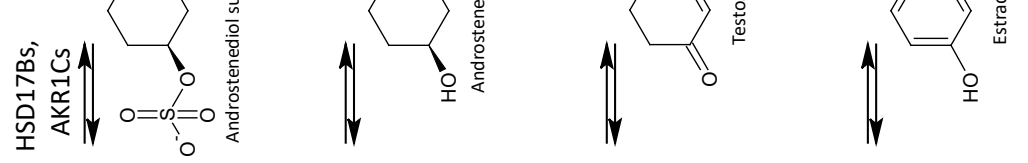

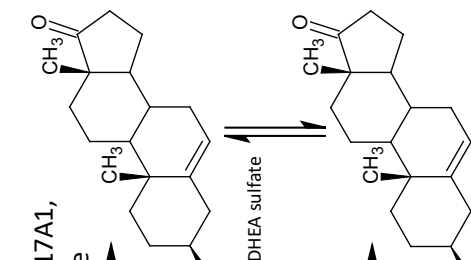

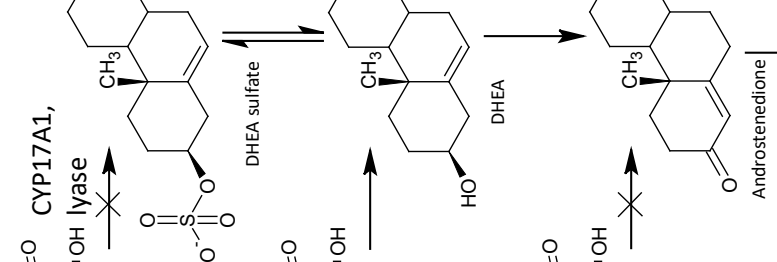
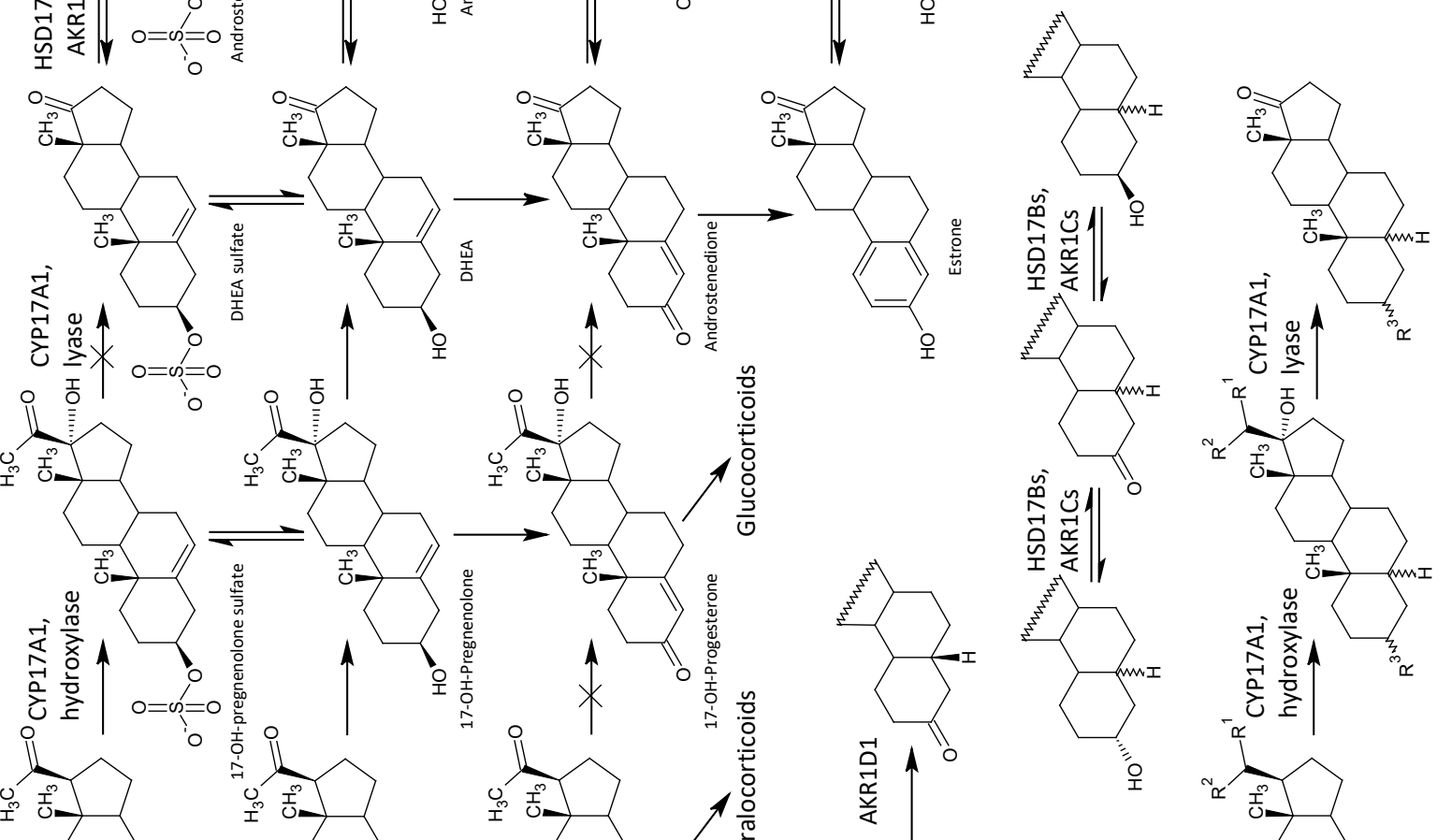

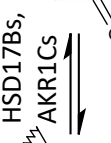

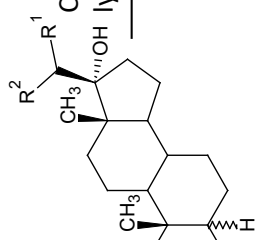

$\sum_{3}^{x}$
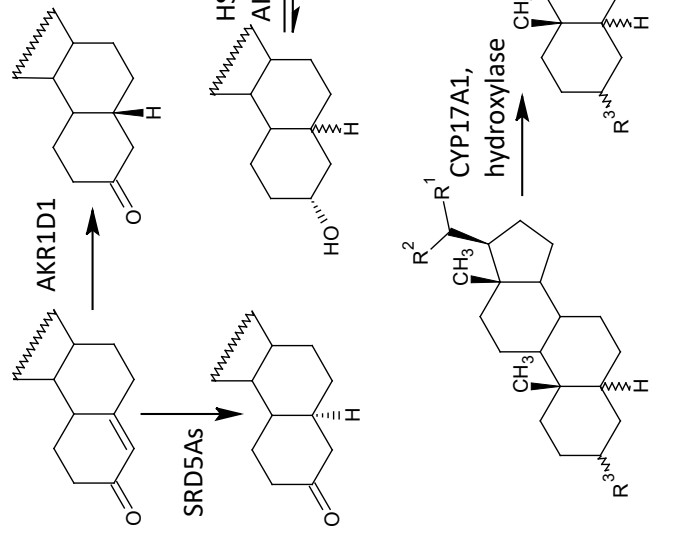

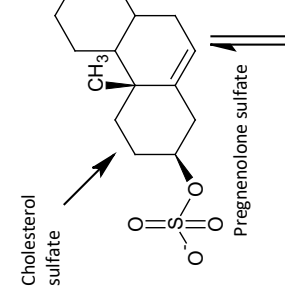

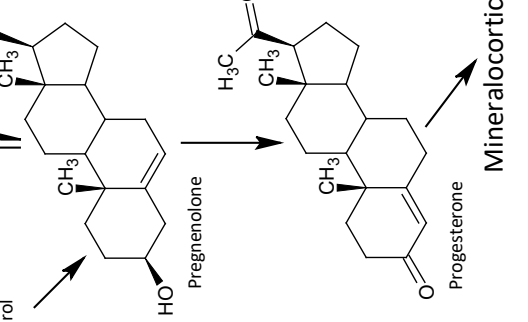




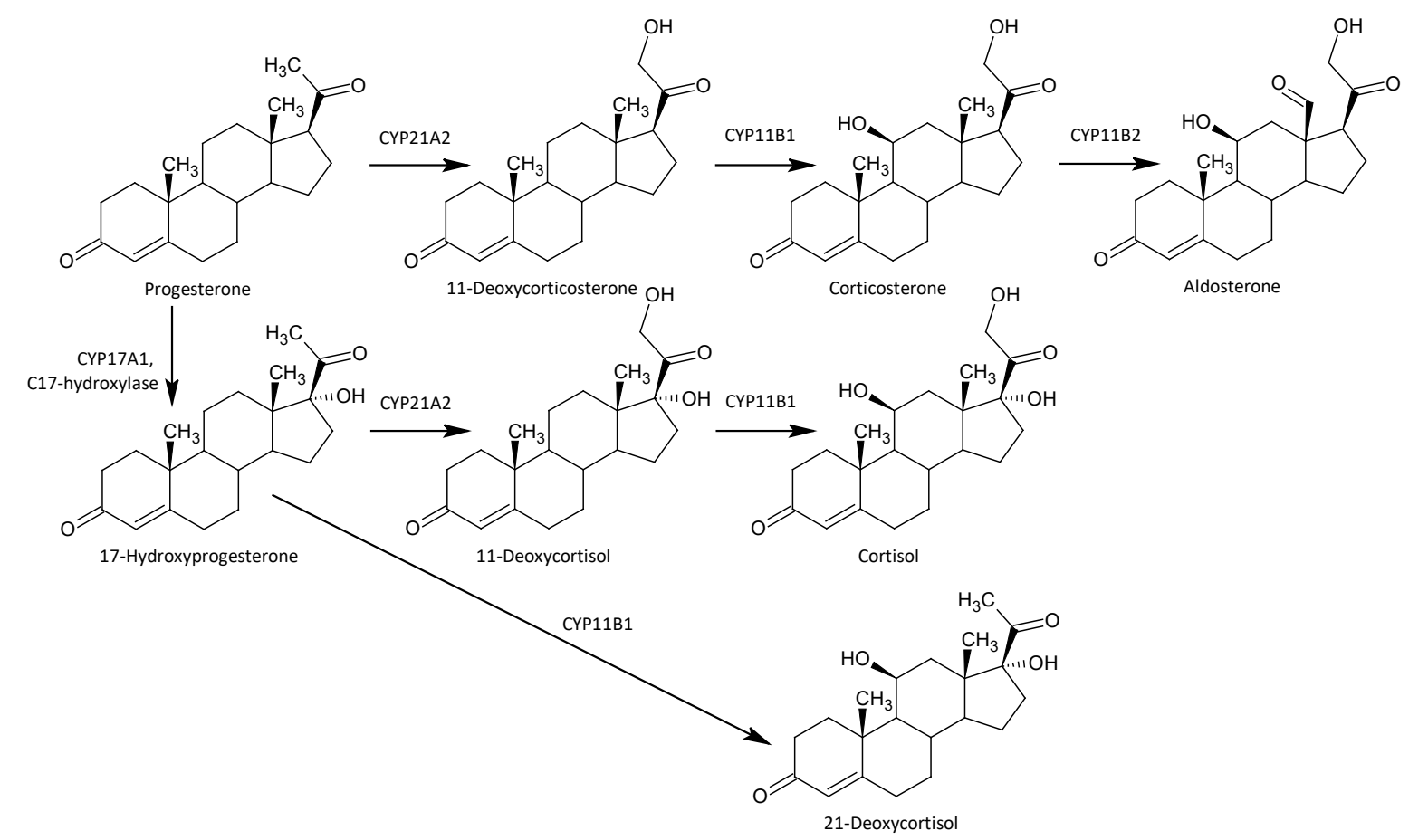

Fig. 2. Simplified scheme of corticosteroid pathways in human.

\section{Chemicals}

Most steroids and deuterated standards were purchased from Steraloids (Newport, RI, USA). The deuterated standard D7 cortisone [2,2,4,6,6,12,12-D7] and trimethylchlorosilane (TMCS) for hydrolysis of steroids conjugates were from Sigma-Aldrich (St. Louis, USA). Sylon BTZ, methoxyamine hydrochloride and all other solvents and chemicals were from Merck (Darmstadt, Germany). All solvents were of HPLC grade.

\section{Stock solutions, calibration standards, and quality control samples}

Stock solutions of external and internal standards (ISs) were prepared in methanol at the concentration of $1 \mathrm{mg} / \mathrm{ml}$. The calibration curve samples (charcoal-stripped plasma with internal and external standards) were prepared in triplicate, blank samples (charcoal-stripped plasma without ISs) were made separately for unconjugated and conjugated steroids as well as zero samples (charcoal-stripped serum with ISs) were prepared. Charcoal-stripped serum was made using a multistep adsorption of steroids on charcoal. The absence of steroids in this matrix was checked by spiking of serum with $\left[{ }^{3} \mathrm{H}\right]$ cortisol $(10,000 \mathrm{dpm} / \mathrm{ml})$ and measurement of the residual radioactivity close to zero. In brief, $100 \mathrm{~g}$ of Activated Charcoal Norit from SigmaAldrich (St. Louis, USA) was mixed with 1 liter of deionized water and let overnight. Then the water with fine particles of the charcoal was decanted, the charcoal was spread out on the filtration paper and let overnight. Then the charcoal was dried at $200{ }^{\circ} \mathrm{C}$ in glass baking bowl for $2 \mathrm{~h}$. The dried charcoal was stored in wide mouth glass reagent bottle. Afterwards, $10^{7} \mathrm{dpm}$ of 3 H cortisol from NEN ${ }^{\circledR}$ Life Science Products (Boston, MA, USA) was added to 1 liter of pooled human serum and $200 \mu 1$ of the mixture was measured in triplicate in scintillation counter $(1,000-2,000 \mathrm{dpm})$. Than the charcoal $(50 \mathrm{~g})$ was mixed with the pooled serum at $4{ }^{\circ} \mathrm{C}$ for $3 \mathrm{~h}$. Then the centrifugation in cooled centrifuge followed at $4{ }^{\circ} \mathrm{C}$ for $20 \mathrm{~min}(3,500 \mathrm{rpm})$. Subsequently, the supernatant was decanted and filtered across the folded filter paper in refrigerator and the filtrate is then mixed with further $50 \mathrm{~g}$ of the charcoal overnight in the refrigerator and afterwards the further filtration followed. The filtrate was then treated (in parts) at $84,000 \mathrm{~g}$ in ultracentrifuge at $4{ }^{\circ} \mathrm{C}$ for $25 \mathrm{~min}$ and the centrifugation was repeated until the serum was free of charcoal particles. Finally, the $200 \mu 1$ of the treated serum was measured (in triplicate) for $3 \mathrm{H}$ radioactivity together with the $200 \mu 1$ of water (in triplicate) as negative control and the results were compared with initial activity of the 3H cortisol spiked serum.

Quality control (QC) samples were prepared using different serum pools from adult men, women in follicular menstrual phase and women in luteal menstrual phase, pregnant women (week 28-42 of pregnancy) and 
from mixed umbilical cord serum, which was collected at labor (week 28-42 of pregnancy). Using five pools differing according to gender, menstrual phase, pregnancy status and matrix (mixed umbilical serum) the QC control samples contained substantially different steroid levels covering gender differences and distinct physiological status in women. The number of samples in mixed pools in individual groups out of pregnancy was greater than 100 for each group, while the sample numbers for the groups of pregnant women and mixed umbilical serum were greater than 30 for each group.

From each stock solution of steroid $(1 \mathrm{mg} / \mathrm{ml})$, $10 \mu \mathrm{l}$ was added into the glass tube. The mixture was dried in vacuum centrifuge $(2 \mathrm{~h})$. Then the stock solutions for calibration samples were prepared in concentrations $5,000,1,000,250,62.5,15.625,3.906,0.977,0.244$, $0.061 \mathrm{ng} / \mathrm{ml}$ in methanol. From these stock solutions $100 \mu \mathrm{l}$ was administered to $10 \mathrm{ml}$ extraction glass tubes vials and the mixtures were dried in the vacuum centrifuge at $45^{\circ} \mathrm{C}$. Then $1 \mathrm{ml}$ of charcoal-stripped serum and the solutions were mixed for $1 \mathrm{~min}$. The next steps were identical for the calibration samples, zero samples, quality control samples and serum samples. The amount of $15 \mu \mathrm{l}$ from the mixed stock solution containing ISs was added to the aforementioned samples. The mixed stock solution of ISs for quantification of unconjugated steroids was prepared from the stock solutions of individual ISs as follows: $10 \mu$ D6-dehydroepiandrosterone (D6-DHEA) ([2,2,3,4,4,6-D6]-DHEA, $1 \mathrm{mg} / \mathrm{ml}), \quad 10 \mu \mathrm{l} \quad$ D8-Prog17 ([2,2,4,6,6,21,21,21-D8]-17 $\alpha$-hydroxyprogesterone,

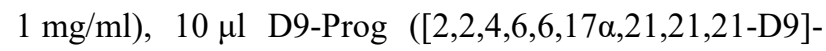
progesterone, $1 \mathrm{mg} / \mathrm{ml}), 100 \mu \mathrm{l}$ D4-cortisol ([9,11,12, 12-D4)-cortisol, $1 \mathrm{mg} / \mathrm{ml}), 50 \mu 1$ D7-cortisone ([2,2,4,6,6, 12,12-D7]-cortisone, $10 \mu \mathrm{g} / \mathrm{ml})$ were mixed, the mixture was dried under the flow of nitrogen and the dry residue was dissolved in $1 \mathrm{ml}$ of methanol. The internal standard of D6-DHEA sulfate ([2,2,3,4,4,6-D6]-DHEA sulfate, $1 \mathrm{mg} / \mathrm{ml}$ ) for quantification of conjugated steroids was prepared similarly. The volume of $50 \mu \mathrm{l}$ D6-DHEA sulfate, $1 \mathrm{mg} / \mathrm{ml}$ ) was dried under the flow of nitrogen and the dry residue was dissolved in $1 \mathrm{ml}$ of methanol.

\section{Sample preparation}

The sample preparation proceeded as follows: after addition of $15 \mu \mathrm{l}$ of the mixed stock solution of ISs for quantification of unconjugated steroids to $1 \mathrm{ml}$ of serum fluid and mixing ( $1 \mathrm{~min})$, the unconjugated steroids were extracted from $1 \mathrm{ml}$ of the mixture with diethyl-ether $(3 \mathrm{ml})$. The diethyl-ether extract was dried in a block heater at $37^{\circ} \mathrm{C}$. The lipids in the dry residue of the diethyl-ether extract were separated by partitioning between a mixture of methanol with water 4:1 $(1 \mathrm{ml})$ and pentane $(1 \mathrm{ml})$. The pentane phase was discarded and the polar phase was dried in a vacuum centrifuge at $60^{\circ} \mathrm{C}$ $(2 \mathrm{~h})$. The dry residue from the polar phase was firstly dissolved in $100 \mu 1$ of acetonitrile. The solution was transferred into the $1 \mathrm{ml}$ conical vial and dried in the flow of nitrogen. The dry residue was derivatized first with a methoxyamine hydrochloride solution in pyridine ( $2 \%)$ $\left(60{ }^{\circ} \mathrm{C}, 1 \mathrm{~h}\right)$ to convert the oxo-groups to methyloxime derivatives. After this first derivatization, the mixture was dried in a flow of nitrogen and the dry residue was treated with the reagent Sylon BTZ $\left(90^{\circ} \mathrm{C}, 24 \mathrm{~h}\right)$. The Sylon BTZ is a mixture of $\mathrm{N}, \mathrm{O}-b i s($ trimethylsilyl)acetamide $(\mathrm{BSA})+$ trimethylchlorosilane (TMCS) + N-trimethylsilylimidazole (TMSI) (3:2:3). This sylilating agent forms trimethylsilyl derivatives on hydroxy-groups (TMS-MOX derivatives). After this second derivatization step, the mixture was dried in the nitrogen flow $(2 \mathrm{~min})$. After administration of approximately $1 \mathrm{mg}$ of ammonium bicarbonate, the residue was partitioned between isooctane $(100 \mu \mathrm{l})$ and $\mathrm{N}, \mathrm{N}$-dimethylformamide $(50 \mu \mathrm{l})$. Then the volume of the vial was mixed $(1 \mathrm{~min})$ and centrifuged for $20 \mathrm{~min}$ at $3,000 \mathrm{rpm}$. The lower, polar layer was aspirated with a Pasteur pipette and the upper non-polar layer remained in the vial for GC-MS/MS analysis. From the upper layer, $2 \mu \mathrm{l}$ was injected into the GC-MS/MS system.

Steroid conjugates remaining in the polar residue after diethyl ether extractions were analyzed as follows: The volume of $15 \mu \mathrm{l}$ D6-DHEA sulfate solution $(50 \mu \mathrm{g} / \mathrm{ml})$ was mixed with this residue (1 min mixing). Then $1 \mathrm{ml}$ of methanol was added and mixed for additional $1 \mathrm{~min}$. After the centrifugation of the mixture (20 min at 3,000 rpm), the upper layer was transferred to the clean $10 \mathrm{ml}$ extraction tube, dried in the vacuum centrifuge at $37^{\circ} \mathrm{C}(5 \mathrm{~h})$, and the dry residues were chemically hydrolyzed according to Dehennin and Peres (1996). Briefly, $1 \mathrm{ml}$ of $1 \mathrm{M}$ TMCS was added to the dry residue of the upper layer and after 1 min mixing, the hydrolysis proceeded for $1 \mathrm{~h}$ at $55^{\circ} \mathrm{C}$. Then $100 \mathrm{mg}$ of sodium bicarbonate was added and after short mixing, the hydrolyzed samples were again dried in the vacuum centrifuge at $37^{\circ} \mathrm{C}(5 \mathrm{~h})$. The dried residues were reconstituted with $500 \mu \mathrm{l}$ of chromatographic water and then further processed in the same way as the free steroids. The calibration samples for the conjugated steroids were prepared similarly as for their unconjugated 
analogues but the standards were mixed with the polar residues after diethyl ether extraction instead of the $1 \mathrm{ml}$ of charcoal-stripped serum.

\section{Instruments and chromatography conditions Instrument settings}

The instrument used was a GCMS-TQ8040 system from Shimadzu (Kyoto, Japan) consisting of a gas chromatograph equipped with an automatic flow control, an AOC-20s autosampler and a triple quadrupole detector with an adjustable electron voltage of $10-195 \mathrm{~V}$. The analysis was conducted in multiple reaction monitoring (MRM) mode. A capillary column with a medium polarity RESTEK Rtx-50 column (diameter $0.25 \mathrm{~mm}$, length $15 \mathrm{~m}$, film thickness $0.1 \mu \mathrm{m}$ ) was used for analyses. Electron-impact ionization with electron voltage fixed at $60 \mathrm{~V}$ and emission current set to $151 \mu \mathrm{A}$ was used for the measurements. The temperatures of the injection port, ion source and interface were maintained at 220,300 , and $310^{\circ} \mathrm{C}$, respectively. Analyses were carried out in the splitless mode with a constant linear velocity of the carrier gas $(\mathrm{He})$, which was maintained at $60 \mathrm{~cm} / \mathrm{s}$. The septum purge flow was set to $3 \mathrm{ml} / \mathrm{min}$. The samples were injected using a high-pressure mode, which was applied at $200 \mathrm{kPa}$ and maintained for $1 \mathrm{~min}$. The detector voltage was set to $2.2 \mathrm{kV}$. The temperature program was as follows: 1 min delay at $80^{\circ} \mathrm{C}$, increase to $190^{\circ} \mathrm{C}\left(40{ }^{\circ} \mathrm{C} / \mathrm{min}\right)$, increase to $210^{\circ} \mathrm{C}\left(6^{\circ} \mathrm{C} / \mathrm{min}\right)$, increase to $300{ }^{\circ} \mathrm{C}\left(20^{\circ} \mathrm{C} / \mathrm{min}\right)$, increase to $320^{\circ} \mathrm{C}$ $\left(40{ }^{\circ} \mathrm{C} / \mathrm{min}\right), 4 \mathrm{~min}$ delay at $320^{\circ} \mathrm{C}$, initial pressure $34 \mathrm{kPa}$, injector temperature $220^{\circ} \mathrm{C}$, analysis duration $16.08 \mathrm{~min}$.

\section{Optimization of method sensitivity}

To optimize method sensitivity, the analysis was carried out using two separately injected aliquots $(2 \mu \mathrm{l})$ for two different groups of steroids for each sample (Table 1). The injection volume of samples was $2 \mu \mathrm{l}$. However, two steroid sulfates injected in the second aliquot exceeded the upper limit of linear dynamic range (LDR). To quantify these analytes, this measurement was repeated using the third aliquot with reduced injection volume $(0.2 \mu \mathrm{l})$. The list of analytes with corresponding abbreviations, correlation coefficients (characterizing the linearity of the response) and the respective LDRs with indication of the abundant steroid conjugates quantified in the third aliquot are shown in Table 2.
For further improvement of sensitivity, the method used time-programmed MRM acquisition. The number of injection aliquot, number of time-programmed MRM acquisition window (AW), MRM transitions with corresponding optimum collision energies for individual steroids and ISs for the corresponding steroids are shown in Table 1. The optimization of collision energies for individual steroids was performed using the Microsoft Excel Macro-Enabled Worksheet named "MRM Optimization Tool" from Shimadzu (Kyoto, Japan).

The number of qualifiers ranged from no qualifier to three qualifiers with respect to the fragmentation patterns of individual steroid derivatives and sensitivity of the method, which is inversely related with the number of MRM transitions in the given AW (Table 1). For instance, in the case of 21-deoxycortisol (DOF) just a single MRM transition was selected $517>427(12 \mathrm{~V})$ as the quantifier without a qualifier, because only this transition had a satisfactory response (Table 1). The case of PD $3 \beta 5 \alpha 20 \alpha$ was similar. In addition, the respective AW 7 included a relatively high number of transitions, which limited the sensitivity. On the other hand, in the AW 1, the androstanediols were measured using three confirmation MRM transitions as the total number of transitions in AW 1 was low (Table 1).

\section{Selection of internal standards}

To represent different chemical and physical properties of various steroid molecules we originally tried to use a maximum number of available ISs. However, we also respected the number of deuterium atoms in the steroid molecule, which is sufficient for separation of the signals from non-deuterated steroid and its deuterated counterpart and, at the same time, wide concentration range of steroids in serum samples, and isotopic purity of the ISs. In addition, we also considered an inverse relationship between the number of MRM-transitions in acquisition windows and sensitivity of the assay. Therefore, from the original number of 16 deuterated steroids we selected five deuterated standards with different polarity such as D6-DHEA sulfate (IS1), D6-DHEA (IS2), D8-Prog17 (IS3), D9-Prog (IS4), D4-cortisol (IS5), and D7-cortisone (IS6). For the conjugated steroids, only IS1 was applicable, because the remaining ISs were instable during the hydrolysis. Therefore, for the quantification of steroid conjugates, the IS1 was used instead of IS3 and IS4 (Table 1). 


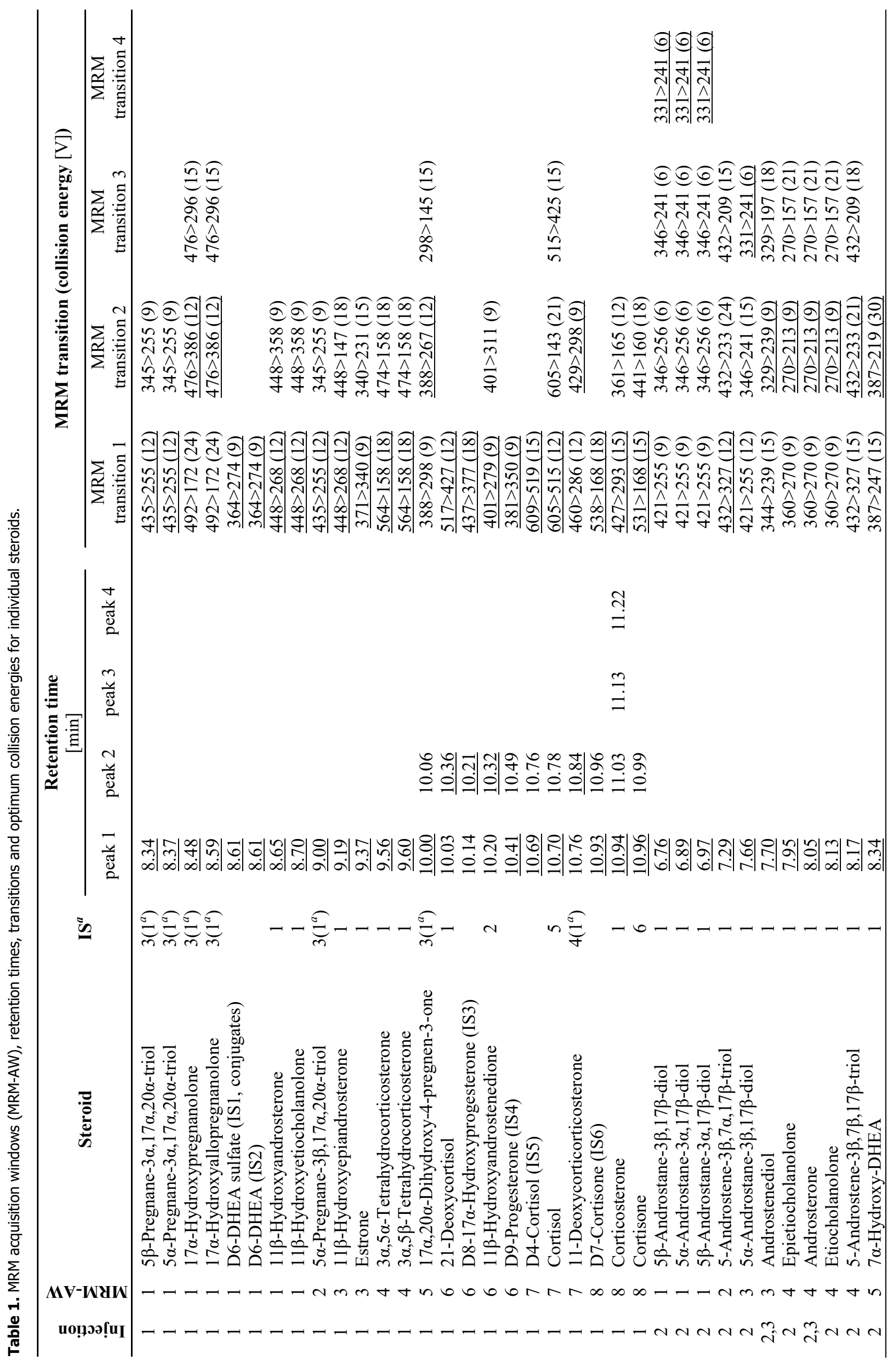




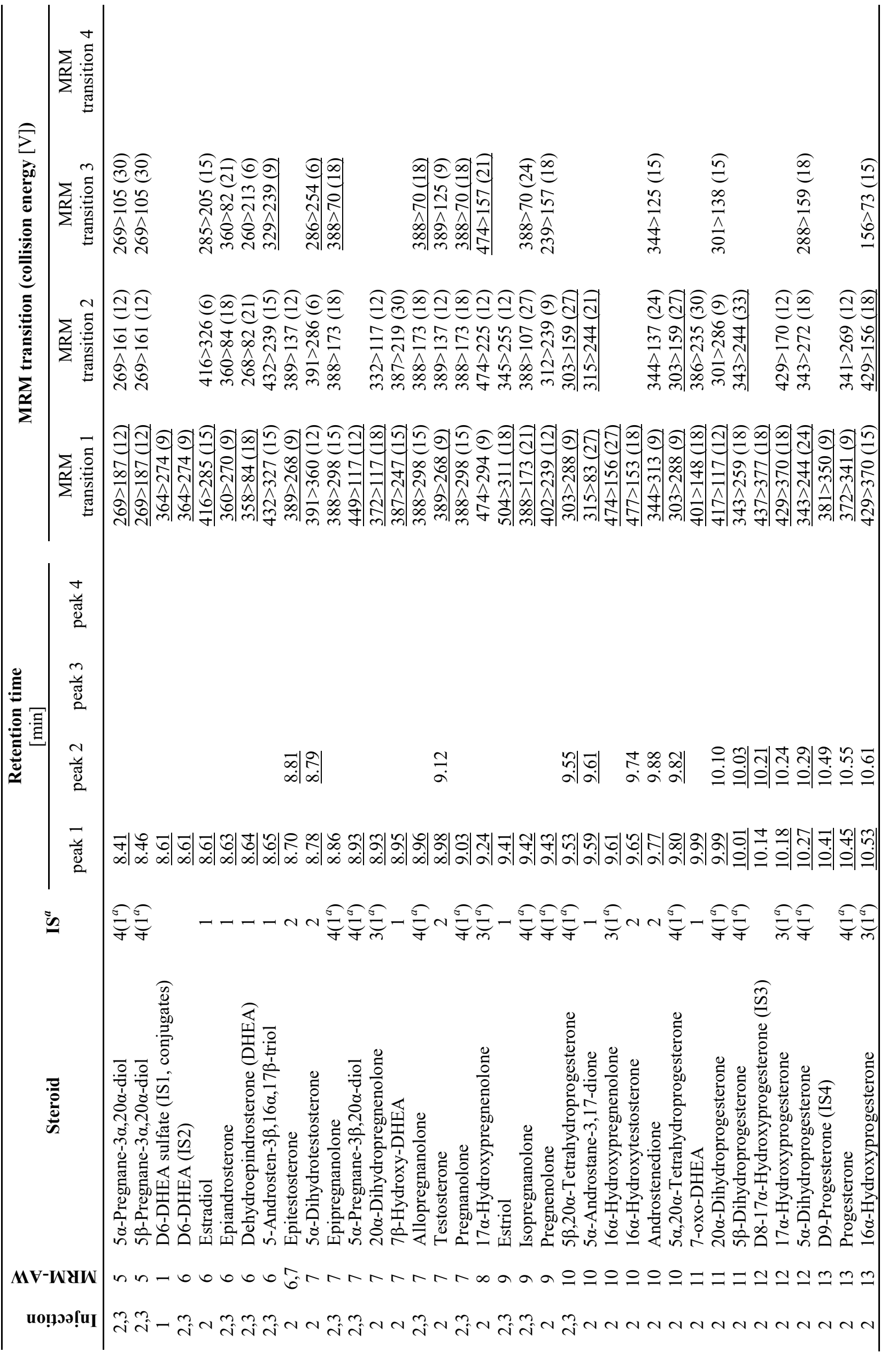


Table 2. List of abbreviations for endogenous steroids, linearity of the response and linear dynamic range.

\begin{tabular}{|c|c|c|c|c|}
\hline ID & Abbreviation & Steroid & $\begin{array}{c}\text { Correlation } \\
\text { coefficient } \\
r\end{array}$ & $\begin{array}{c}\text { Linear dynamic range } \\
{[\mathrm{pg} \text { injected }]}\end{array}$ \\
\hline 1 & Preg & Pregnenolone & 0.9995 & $0.077-2000$ \\
\hline 2 & Preg17 & $17 \alpha$-Hydroxypregnenolone & 0.9996 & $0.12-2000$ \\
\hline 3 & Preg16 $\alpha$ & 16 $\alpha$-Hydroxypregnenolone & 0.9997 & $0.12-2000$ \\
\hline 4 & DHPreg20 $\alpha$ & $20 \alpha$-Dihydropregnenolone & 0.9991 & $0.12-2000$ \\
\hline 5 & DHEA & Dehydroepiandrosterone & 0.9978 & 07.08 .2000 \\
\hline 6 & DHEA $7 \alpha$ & $7 \alpha$-Hydroxy-DHEA & 0.9995 & $0.12-2000$ \\
\hline 7 & DHEA7o & 7-oxo-DHEA & 0.9952 & $0.49-2000$ \\
\hline 8 & DHEA7 $\beta$ & 7ß-Hydroxy-DHEA & 0.9987 & $0.49-2000$ \\
\hline 9 & 5-Adiol & 5-Androstene- $3 \beta, 17 \beta$-diol & 0.9979 & $0.49-2000$ \\
\hline 10 & $\operatorname{AT} 7 \alpha$ & 5-Androstene- $3 \beta, 7 \alpha, 17 \beta$-triol & 0.9999 & $0.49-2000$ \\
\hline 11 & AT7 $\beta$ & 5-Androstene- $3 \beta, 7 \beta, 17 \beta$-triol & 0.9993 & $0.12-2000$ \\
\hline 12 & AT16 $\alpha$ & 5 -Androstene- $3 \beta, 16 \alpha, 17 \beta$-triol & 0.9985 & $0.49-2000$ \\
\hline 13 & $\mathrm{P}$ & Progesterone & 0.9998 & $0.12-10000$ \\
\hline 14 & $\mathrm{P} 17$ & $17 \alpha$-Hydroxyprogesterone & 0.9997 & $0.12-2000$ \\
\hline 15 & DHP $17 \alpha 20 \alpha$ & $17 \alpha, 20 \alpha$-Dihydroxy-4-pregnene-3-one & 0.9957 & $0.12-10000$ \\
\hline 16 & $\mathrm{P} 16 \alpha$ & 16 $\alpha$-Hydroxyprogesterone & 0.9998 & $0.12-2000$ \\
\hline 17 & DHP20 $\alpha$ & $20 \alpha$-Dihydroprogesterone & 0.9997 & $0.49-2000$ \\
\hline 18 & A4 & Androstenedione & 0.9988 & $0.49-2000$ \\
\hline 19 & $\mathrm{~T}$ & Testosterone & 0.9998 & $2.0-2000$ \\
\hline 20 & $\mathrm{~T} 16 \alpha$ & $16 \alpha$-Hydroxytestosterone & 0.9997 & $2.0-2000$ \\
\hline 21 & DHT5 $\alpha$ & $5 \alpha$-Dihydrotestosterone & 0.9994 & $0.49-2000$ \\
\hline 22 & E1 & Estrone & 0.9995 & $7.8-10000$ \\
\hline 23 & E2 & Estradiol & 0.9996 & $0.12-2000$ \\
\hline 24 & E3 & Estriol & 0.9999 & $7.8-10000$ \\
\hline 25 & DHP5 $\alpha$ & $5 \alpha$-Dihydroprogesterone & 0.9995 & $0.12-10000$ \\
\hline 26 & THP $3 \alpha 5 \alpha$ & Allopregnanolone & 0.9996 & $0.12-2000$ \\
\hline 27 & THP3 $\beta 5 \alpha$ & Isopregnanolone & 0.9995 & $0.49-2000$ \\
\hline 28 & DHP5 $\beta$ & $5 \beta$-Dihydroprogesterone & 0.9986 & $7.8-10000$ \\
\hline 29 & THP $3 \alpha 5 \beta$ & Pregnanolone & 0.9995 & $0.12-2000$ \\
\hline 30 & ТHР $3 \beta 5 \beta$ & Epipregnanolone & 0.9996 & $0.12-2000$ \\
\hline 31 & THP5 $\alpha 20 \alpha$ & $5 \alpha, 20 \alpha$-Tetrahydroprogesterone & 0.9995 & $0.12-2000$ \\
\hline 32 & $\operatorname{PD} 3 \alpha 5 \alpha 20 \alpha$ & $5 \alpha$-Pregnane- $3 \alpha, 20 \alpha$-diol & 0.9995 & $0.12-10000$ \\
\hline 33 & PD $3 \beta 5 \alpha 20 \alpha$ & $5 \alpha$-Pregnane- $3 \beta, 20 \alpha$-diol & 0.9987 & $7.8-10000$ \\
\hline 34 & THP5 $\beta 20 \alpha$ & $5 \beta, 20 \alpha$-Tetrahydroprogesterone & 0.9999 & $0.12-2000$ \\
\hline 35 & PD $3 \alpha 5 \beta 20 \alpha$ & $5 \beta$-Pregnane- $3 \alpha, 20 \alpha$-diol & 0.9995 & $0.12-2000$ \\
\hline 36 & PD3 $\beta 5 \beta 20 \alpha$ & $5 \beta$-Pregnane- $3 \beta, 20 \alpha$-diol & 0.9997 & $0.49-10000$ \\
\hline 37 & PD3 $35 \alpha \alpha 17$ & $17 \alpha$-Hydroxyallopregnanolone & 0.9994 & $0.49-2000$ \\
\hline 38 & $\mathrm{PD} 3 \alpha 5 \beta 17$ & 17 $\alpha$-Hydroxypregnanolone & 0.9995 & $0.49-2000$ \\
\hline 39 & РТ $3 \alpha 5 \alpha 17 \alpha 20 \alpha$ & $5 \alpha$-Pregnane- $3 \alpha, 17 \alpha, 20 \alpha$-triol & 0.9981 & $0.12-10000$ \\
\hline 40 & РТ $3 \beta 5 \alpha 17 \alpha 20 \alpha$ & $5 \alpha$-Pregnane- $3 \beta, 17 \alpha, 20 \alpha$-triol & 0.9977 & $0.12-10000$ \\
\hline 41 & РТ $3 \alpha 5 \beta 17 \alpha 20 \alpha$ & $5 \beta$-Pregnane- $3 \alpha, 17 \alpha, 20 \alpha$-triol & 0.9982 & $0.12-10000$ \\
\hline 42 & DHA $5 \alpha$ & $5 \alpha$-Androstane-3,17-dione & 0.9993 & $0.12-10000$ \\
\hline 43 & THA $3 \alpha 5 \alpha$ & Androsterone & 0.9987 & $0.12-2000$ \\
\hline 44 & THA $3 \beta 5 \alpha$ & Epiandrosterone & 0.9991 & $2.0-2000$ \\
\hline 45 & THA $3 \alpha 5 \beta$ & Etiocholanolone & 0.9994 & $0.12-2000$ \\
\hline 46 & $\mathrm{AD} 3 \alpha 5 \alpha 17 \beta$ & $5 \alpha$-Androstane- $3 \alpha, 17 \beta$-diol & 0.9996 & $0.12-2000$ \\
\hline 47 & $\mathrm{AD} 3 \beta 5 \alpha 17 \beta$ & $5 \alpha$-Androstane- $3 \beta, 17 \beta$-diol & 0.9989 & $0.12-2000$ \\
\hline 48 & $\mathrm{AD} 3 \alpha 5 \beta 17 \beta$ & $5 \alpha$-Androstane- $3 \alpha, 17 \beta$-diol & 0.9996 & $0.12-2000$ \\
\hline 49 & $\mathrm{~F}$ & Cortisol & 0.9991 & $31-10000$ \\
\hline 50 & $\mathrm{E}$ & Cortisone & 0.9972 & $125-10000$ \\
\hline 51 & $\mathrm{~B}$ & Corticosterone & 0.9987 & $7.8-10000$ \\
\hline 52 & DOF & 21-Deoxycortisol & 0.9991 & $0.49-2000$ \\
\hline
\end{tabular}


Table 2., continued.

\begin{tabular}{|c|c|c|c|c|}
\hline ID & Abbreviation & Steroid & $\begin{array}{c}\text { Correlation } \\
\text { coefficient } \\
r\end{array}$ & $\begin{array}{c}\text { Linear } \\
\text { dynamic range } \\
{[\mathrm{pg} \text { injected }]}\end{array}$ \\
\hline 53 & DOC & 11-Deoxycorticosterone & 0.9999 & $2-10000$ \\
\hline 54 & THB $3 \alpha 5 \alpha$ & $3 \alpha, 5 \alpha$-Tetrahydrocorticosterone & 0.9995 & $0.12-10000$ \\
\hline 55 & THB $3 \alpha 5 \beta$ & $3 \alpha, 5 \beta$-Tetrahydrocorticosterone & 0.999 & $0.49-10000$ \\
\hline 56 & $11 \mathrm{OHA} 4$ & 11 $\beta$-Hydroxyandrostenedione & 0.9978 & $0.49-10000$ \\
\hline 57 & THA $3 \alpha 5 \alpha 11 \beta$ & $11 \beta$-Hydroxyandrosterone & 0.9998 & $0.12-2000$ \\
\hline 58 & THA $3 \beta 5 \alpha 11 \beta$ & 11ß-Hydroxyepiandrosterone & 0.9983 & $0.12-2000$ \\
\hline 59 & ТНА $3 \alpha 5 \beta 11 \beta$ & $11 \beta$-Hydroxyetiocholanolone & 0.9999 & $0.12-2000$ \\
\hline 60 & PregC & Pregnenolone sulfate & 0.9994 & $0.077-2000$ \\
\hline 61 & Preg17C & $17 \alpha$-Hydroxypregnenolone sulfate & 0.9996 & $0.12-2000$ \\
\hline 62 & DHPreg20 $\alpha \mathrm{C}$ & $20 \alpha$-Dihydropregnenolone sulfate & 0.9991 & $0.12-2000$ \\
\hline 63 & DHEAC & DHEA sulfate & 0.998 & $7.8-2000^{a}$ \\
\hline 64 & 5-AdiolC & Androstenediol sulfate & 0.9981 & $0.49-2000$ \\
\hline 65 & $\mathrm{AT} 16 \alpha \mathrm{C}$ & 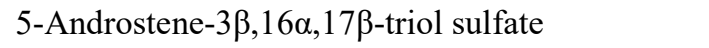 & 0.9986 & $0.49-2000$ \\
\hline 66 & DHP17 $\alpha 20 \alpha C$ & Conjugated $17 \alpha, 20 \alpha$-dihydroxy-4-pregnen-3-one & 0.9945 & $0.12-10000$ \\
\hline 67 & DHP20 $\alpha \mathrm{C}$ & Conjugated $20 \alpha$-dihydroprogesterone & 0.9997 & $0.49-2000$ \\
\hline 68 & $\mathrm{TC}$ & Conjugated testosterone & 0.9993 & $2.0-2000$ \\
\hline 69 & EpiTC & Conjugated epitestosterone & 0.9997 & $0.49-2000$ \\
\hline 70 & $\mathrm{E} 1 \mathrm{C}$ & Estrone sulfate & 0.9993 & $7.8-10000$ \\
\hline 71 & $\mathrm{E} 2 \mathrm{C}$ & Estradiol sulfate & 0.9991 & $0.12-2000$ \\
\hline 72 & $\mathrm{E} 3 \mathrm{C}$ & Estriol sulfate & 0.9994 & $7.8-10000$ \\
\hline 73 & THP $3 \alpha 5 \alpha \mathrm{C}$ & Allopregnanolone sulfate & 0.9995 & $0.12-2000$ \\
\hline 74 & $\mathrm{THP} 3 \beta 5 \alpha \mathrm{C}$ & Isopregnanolone sulfate & 0.9997 & $0.49-2000$ \\
\hline 75 & $\mathrm{THP} 3 \alpha 5 \beta \mathrm{C}$ & Conjugated pregnanolone & 0.9994 & $0.12-2000$ \\
\hline 76 & THP $3 \beta 5 \beta \mathrm{C}$ & Conjugated epipregnanolone & 0.9994 & $0.12-2000$ \\
\hline 77 & THP $5 \alpha 20 \alpha C$ & Conjugated $5 \alpha, 20 \alpha$-tetrahydroprogesterone & 0.9986 & $0.12-2000$ \\
\hline 78 & $\mathrm{PD} 3 \alpha 5 \alpha 20 \alpha \mathrm{C}$ & Conjugated $5 \alpha$-pregnane- $3 \alpha, 20 \alpha$-diol & 0.9994 & $0.12-10000$ \\
\hline 79 & $\mathrm{PD} 3 \beta 5 \alpha 20 \alpha \mathrm{C}$ & Conjugated $5 \alpha$-pregnane- $3 \beta, 20 \alpha$-diol & 0.9981 & $7.8-10000$ \\
\hline 80 & THP5 $\beta 20 \alpha C$ & Conjugated $5 \beta, 20 \alpha$-tetrahydroprogesterone & 0.9998 & $0.12-2000$ \\
\hline 81 & $\mathrm{PD} 3 \alpha 5 \beta 20 \alpha \mathrm{C}$ & Conjugated $5 \beta$-pregnane- $3 \alpha, 20 \alpha$-diol & 0.9995 & $0.12-2000$ \\
\hline 82 & $\mathrm{PD} 3 \beta 5 \beta 20 \alpha \mathrm{C}$ & Conjugated $5 \beta$-pregnane- $3 \beta, 20 \alpha$-diol & 0.9994 & $0.49-10000$ \\
\hline 83 & $\mathrm{PD} 3 \alpha 5 \alpha 17 \mathrm{C}$ & $17 \alpha$-Hydroxyallopregnanolone sulfate & 0.9994 & $0.49-2000$ \\
\hline 84 & $\mathrm{PD} 3 \alpha 5 \beta 17 \mathrm{C}$ & Conjugated $17 \alpha$-hydroxypregnanolone & 0.9996 & $0.49-2000$ \\
\hline 85 & РТ $3 \alpha 5 \alpha 17 \alpha 20 \alpha$ & $5 \alpha$-Pregnane- $3 \alpha, 17 \alpha, 20 \alpha$-triol & 0.9981 & $0.12-10000$ \\
\hline 86 & РТ $3 \beta 5 \alpha 17 \alpha 20 \alpha$ & $5 \alpha$-Pregnane- $3 \beta, 17 \alpha, 20 \alpha$-triol & 0.9977 & $0.12-10000$ \\
\hline 87 & РТ $3 \alpha 5 \beta 17 \alpha 20 \alpha$ & $5 \beta$-Pregnane- $3 \alpha, 17 \alpha, 20 \alpha$-triol & 0.9982 & $0.12-10000$ \\
\hline 88 & THA $3 \alpha 5 \alpha \mathrm{C}$ & Androsterone sulfate & 0.9987 & $0.12-2000^{a}$ \\
\hline 89 & THA $3 \beta 5 \alpha \mathrm{C}$ & Epiandrosterone sulfate & 0.9993 & $2.0-2000^{a}$ \\
\hline 90 & THA $3 \alpha 5 \beta C$ & Etiocholanolone sulfate & 0.9995 & $0.12-2000$ \\
\hline 91 & THA $3 \beta 5 \beta C$ & Epietiocholanolone sulfate & 0.9992 & $0.49-2000$ \\
\hline 92 & $\mathrm{AD} 3 \alpha 5 \alpha 17 \beta \mathrm{C}$ & Conjugated $5 \alpha$-androstane- $3 \alpha, 17 \beta$-diol & 0.9994 & $0.12-2000$ \\
\hline 93 & $\mathrm{AD} 3 \beta 5 \alpha 17 \beta \mathrm{C}$ & Conjugated $5 \alpha$-androstane- $3 \beta, 17 \beta$-diol & 0.9996 & $0.12-2000$ \\
\hline 94 & $\mathrm{AD} 3 \alpha 5 \beta 17 \beta \mathrm{C}$ & Conjugated $5 \beta$-androstane- $3 \alpha, 17 \beta$-diol & 0.9992 & $0.12-10000$ \\
\hline 95 & $\mathrm{AD} 3 \beta 5 \beta 17 \beta \mathrm{C}$ & Conjugated $5 \beta$-androstane- $3 \beta, 17 \beta$-diol & 0.9992 & $0.12-10000$ \\
\hline 96 & THB $3 \alpha 5 \alpha \mathrm{C}$ & Conjugated $3 \alpha, 5 \alpha$-tetrahydrocorticosterone & 0.9994 & $0.12-10000$ \\
\hline 97 & THB3 $\alpha 5 \beta C$ & Conjugated $3 \alpha, 5 \beta$-tetrahydrocorticosterone & 0.9994 & $0.12-10000$ \\
\hline 98 & THA $3 \alpha 5 \alpha 11 \beta C$ & $11 \beta$-Hydroxyandrosterone sulfate & 0.998 & $0.12-2000$ \\
\hline 99 & THA $3 \beta 5 \alpha 11 \beta C$ & $11 \beta$-Hydroxyepiandrosterone sulfate & 0.9985 & $0.12-2000$ \\
\hline 100 & THA $3 \alpha 5 \beta 11 \beta \mathrm{C}$ & $11 \beta$-Hydroxyetiocholanolone sulfate & 0.9982 & $0.12-2000$ \\
\hline
\end{tabular}

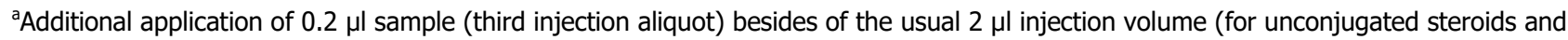
most steroid conjugates - first and second injection aliquots) to quantify two steroid conjugates above the upper limit of the linear dynamic range. 


\section{Independent analytical methods used for accuracy testing}

To compare some results of the present method, we measured 47 analytes using our previously published GC-MS method (Hill et al. 2010b), 6 analytes by our LC-MS/MS method (Vitku et al. 2016) and cortisol was also measured by radioimmunoassay from Immunotech (Marseille, France).

\section{Method performance characteristics}

\section{Calibration curve and linearity of the response}

The calibration was performed in charcoalstripped serum. The analytes were quantified using calibration curves based on known concentrations in the mixtures of analyzed standards with constant level of ISs. We used a 9-point logarithmic calibration curve. The values were corrected for procedural losses according to yields of ISs. The use of ISs for individual steroids is shown in Table 1. The amount of each steroid injected from the calibration samples into the GC-corresponded to amount of $10 \mathrm{ng}, 2 \mathrm{ng}, 500 \mathrm{pg}, 125 \mathrm{pg}, 31.2 \mathrm{pg}, 7.81 \mathrm{pg}$, $1.95 \mathrm{pg}, 488 \mathrm{fg}$ and $122 \mathrm{fg}$. The calibration curves were constructed by plotting the logarithm of response factor (analyte area/internal standard area) against the logarithm of concentration of the calibration (external) standard to cover the large concentration differences for circulating steroids in different physiological and pathophysiological situations and even more explicit contrasts between unconjugated steroids and their conjugated counterparts at appropriate number of calibration points. This arrangement also provided equal weights for individual calibration points in the logarithmic calibration curve and therefore the use of weighted regression model was not necessary to apply. The assay acceptance criterion for each back-calculated standard concentration was set $15 \%$ deviation from the nominal value.

\section{Precision}

The method precision (intra-assay, within-day) and intermediate precision (inter-assay, between-day) was based on the concentrations of each analyte. Regarding gender differences in the levels of testosterone and its metabolites, elevated levels of progesterone and its metabolites in the luteal menstrual phase and excessive levels of numerous steroids in serum from pregnant women and in umbilical cord serum, the precision was evaluated separately in pooled sera for adult men, women in the follicular menstrual phase, luteal menstrual phase, pregnant women at labor and for mixed umbilical cord sera at labor. The method precision was calculated from steroid concentrations in six identical samples, which were prepared from the aforementioned pools within one batch prepared on the same day. Similarly, intermediate precision was estimated from the steroid concentrations in six identical samples but these were prepared in separate batches on different days. The precision was expressed as percent of relative standard deviation (RSD).

\section{Recovery}

The recovery indicates the extraction efficiency of an analytical process, reported as a percentage of the known amount of an analyte carried through the sample extraction and processing steps of the method (Bioanalytical Method Validation 2018). In the present method, the recovery was determined by spiking charcoal-stripped serum with three concentrations of the individual analytes taking into account steroid levels in the corresponding pools. The recovery experiments were performed by comparing the analytical results of extracted samples with corresponding extracts of blanks spiked with the analyte post-extraction (Bioanalytical Method Validation 2018) in replicates from four independent runs.

\section{Accuracy}

Accuracy was expressed as relative error of the measured concentration of each steroid with respect to its true spiked concentration (\% bias). The accuracy testing was performed for three different concentrations of analytes dissolved in charcoal-stripped plasma, which were close to their physiological levels. The bias was tested in both intra- and inter-day experiments. The corresponding samples for accuracy testing were processed in the same way as the calibration and unknown samples (see section Stock solutions, calibration standards, and quality control samples and section Sample preparation). The bias less then $\pm 15 \%$ was met for all analytes in all tested concentrations in both intra- and inter-day experiments. The analytes, which did not meet these criteria, were not included in this method.

Furthermore, we compared our present GC-MS/MS method with our previous GC-MS method for 45 steroids in samples covering all types of human sera (Table S1) and also tested an agreement of six common steroids (pregnenolone, 17 $\alpha$-hydroxypregenolone, DHEA, androstenedione, testosterone and cortisol) 
measured by our present method with the LC-MS/MS method (Hill et al. 2010b) in samples mostly consisting of the women in follicular menstrual phase but there were also some women in the luteal phase, postmenopausal women and men (Table S2). Besides the LC-MS/MS and GC-MS/MS, the cortisol was also evaluated using an RIA kit from Immunotech (Marseille, France). The comparison was performed using Bland-Altman procedure (Bland and Altman 1986) and a robust Passing Bablok regression with the use of R library "mcr" (Manuilova et al. 2014).

\section{Limit of detection and limit of quantification}

Because the baseline noise was accessible for all analytes in all matrixes (pools), the limit of detection (LOD) and limit of quantification (LOQ) were estimated using charcoal stripped plasma spiked with steroids in three levels covering gender differences and distinct physiological status in women. The LOD was calculated as 3.3 times of the baseline noise using charcoal stripped plasma vs. charcoal stripped plasma spiked with steroid on the first level with lowest concentration of analyte.

The lowest nonzero standard on the calibration curve defined the LOQ. The satisfactory analyte response at the LOQ in the present method was at least five times the analyte response of the zero calibrator and the satisfactory bias at the LOQ was at most $\pm 20 \%$ of nominal concentration. Similarly, the satisfactory imprecision at the LOQ was at most $\pm 20 \%$ RSD. For this purpose, we tested the replicates prepared in six runs (Bioanalytical Method Validation 2018). The determination of signal to noise ratios $(\mathrm{S} / \mathrm{N})$ for the calculation of LOD was completed using a functionality in the Shimadzu software GCMSsolution Version 4.20, which was a component of our GC-MS/MS system.

\section{Efficiency of methanolysis and stability of non-deuterated} and deuterated steroids

Unfortunately, the external standards for steroid sulfates and glucuronides are not available for the full spectrum of the quantified steroid conjugates. Therefore, we have tested the efficiency of methanolysis for only seven sulfated non-deuterated steroids ( 6 sulfates and one disulfate) and D6-dehydroepiandrosterone sulfate (D6-DHEA). The procedure was as follows. The $100 \mu \mathrm{l}$ or $10 \mu 1$ aliquots of the stock solution of unconjugated steroid and sulfated steroid were administered into the glass extraction tubes and dried under the flow of nitrogen. Then $20 \mu \mathrm{l}$ of methanol was added and the solution was shortly mixed. The addition of $1 \mathrm{ml}$ of charcoal-stripped mixed human plasma followed and the solution was then mixed for $1 \mathrm{~min}$. The obtained samples for each steroid or steroid sulfate were processed in the same way as the calibration and unknown samples (see section Stock solutions, calibration standards, and quality control samples and section Sample preparation). The responses (areas under the peak) for polar and non-polar phases after diethyl ether extraction for individual unconjugated steroids, corresponding steroid conjugates and for internal standard (D6-DHEA) were used to calculate extraction efficiency for unconjugated steroids and sulfated steroids, as well as the efficiency of methanolysis in sulfated steroids.

The analysis of chemical stability during the methanolysis for unconjugated steroids was based on the comparison of calibration samples for unconjugated analytes, which were exposed to methanolysis procedure with the same samples, which did not undergo this route.

\section{Terminology of steroid polar conjugates}

Concerning the terminology of the steroid polar conjugates used here, the term steroid sulfate was used in the case of the dominance of $3 \alpha / \beta$-monosulfate over other forms of steroid conjugates, while the term conjugated steroid was used in the case of comparable amounts of conjugate forms (sulfates, disulfates, and glucuronides). This terminology was based on the relevant literature, with appropriate citations for each steroid as follows: Preg sulfate (Brochu and Belanger 1987, Sanchez-Guijo et al. 2015), DHPreg20 $\alpha$ sulfate, dehydroepiandrosterone (DHEA) sulfate (Brochu et al. 1987, Labrie et al. 1997, Sanchez-Guijo et al. 2015), 5-Adiol sulfate (Labrie et al. 1997, Sanchez-Guijo et al. 2015), ТНP $3 \alpha 5 \alpha$ sulfate, ТНР $3 \beta 5 \alpha$ sulfate (Abu-Hayyeh et al. 2013), conjugated THP $3 \alpha 5 \beta$ (sulfate + glucuronide) (Meng et al. 1997), PD5 $\alpha 3 \beta 20 \alpha$ sulfate

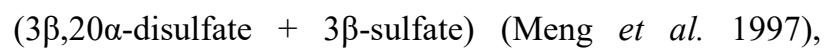
conjugated PD3 $\alpha 5 \beta 20 \alpha(3 \beta, 20 \alpha$-disulfate $+3 \beta$-sulfate + glucuronide) (Meng et al. 1997), THA3 $\alpha 5 \alpha$ sulfate (Labrie et al. 1997, Sanchez-Guijo et al. 2015), THA3 $\beta 5 \alpha$ sulfate (Labrie et al. 1997, Sanchez-Guijo et al. 2015), THA sulfate $3 \alpha 5 \beta$ (Tokushige et al. 2013), THA sulfate $3 \beta 5 \beta$, conjugated (glucuronide + sulfate) (Labrie et al. 1997), and conjugated $\mathrm{AD} 3 \beta 5 \alpha 17 \beta$ (sulfate + glucuronide) (Labrie et al. 1997). 


\section{Results and Discussion}

In total, the levels of 100 analytes (58 unconjugated steroids and 42 steroid conjugates) were quantified in samples of pooled sera from groups of adult men, women in the follicular menstrual phase, women in the luteal menstrual phase, pregnant women at labor and in umbilical cord serum at labor (Tables 2 and 3). The steroid metabolome in the maternal circulation included the levels of $\mathrm{C} 21 \Delta^{5}$ steroids, C19 $\Delta^{5}$ steroids, C21 $\Delta^{4}$ steroids, C19 $\Delta^{4}$ steroids, estrogens, $\mathrm{C} 21$ and $\mathrm{C} 195 \alpha / \beta$-reduced steroids, 7 $\alpha$-hydroxy-, 16 $\alpha$-hydroxy-, 7 $\beta$-hydroxy- and 7-oxo-

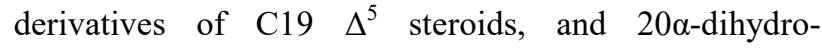
metabolites of C21 steroids (20 $\alpha$-dihydro-pregnanes) (Table 2). Figures 3-6 show a comparison of the chromatograms for calibration samples and samples prepared from five pools of human serum and recorded on quantification MRM transitions for unconjugated steroids, which are less abundant then their conjugated counterparts (Table 3 ).

\section{Validation parameters}

Linearity of the response

Sufficient linearity was found for broad range of concentrations (Table 2). The $15 \%$ deviation from the nominal value for each back-calculated standard concentration as the criterion of assay acceptance was not exceeded in any case.

\section{Precision}

As expected, the higher precision was typically obtained for more abundant steroids. For instance, better results were obtained for $\mathrm{C} 19$ steroids in non-pregnant subjects but for C21 steroids in pregnant women and in mixed umbilical serum. Higher precision was achieved for more abundant steroid conjugates when compared with their less abundant unconjugated counterparts. The results for T, DHT5 $\alpha$ and 5-Adiol were generally better in pooled serum from adult men when compared with other groups. As concerns the accessibility of hydroxy-group for derivatization, the 11ß-hydroxy-steroids showed lower precision when compared with their 11-deoxycounterparts due to difficult accessibility of $11 \beta$-hydroxygroup for the sylilating agent.

If the intra- and/or inter-assay exceeded the $15 \%$ RSD in some of the tested pooled samples, the validation in this biological material was considered as unsatisfactory. For instance, the levels of several reduced
$5 \beta$-reduced C21 steroids are insufficient to quantify these analytes out of pregnancy. However, in a nutshell, most analytes may be quantified in all investigated matrixes (Table 3).

\section{Recovery}

In general, the additions of steroids for the computation of recovery were derived from steroid levels in the pooled sample. In two steroid sulfates such as DHEA sulfate and THA $3 \alpha 5 \alpha \mathrm{C}$, the samples for recovery were diluted to be within the LDR (Table S3). As expected, the recovery rates differed according to the steroid polarity. On the one hand, the diethyl-ether extraction step should be more favorable for the less polar steroids but on the other hand, partitioning between the methanol-water mixture and pentane should be less efficient for the steroids with low polarity. When testing the recovery, we found lower values for less polar steroids such as $5 \alpha / \beta$ reduced C21 steroids but high values for the polar ones such as cortisol. The number of hydroxy-groups positively correlates with the recovery rate (for instance allopregnanolone vs. $5 \alpha$-pregnane-3 $\alpha, 20 \alpha$-diol or allopregnanolone vs. 17-hydroxyallopregnanolone). The $5 \alpha / \beta$-reduced steroids showed lower recovery rates in comparison with their unsaturated counterparts (for instance $5 \alpha$-dihydroprogesterone vs. progesterone or $5 \alpha$-dihydrotestosterone vs. testosterone). The C19 steroids generally exhibit higher recovery rates in comparison with their C21 analogues (for instance androsterone vs. allopregnanolone).

\section{Accuracy}

The accuracy test was not carried out if the intraand/or inter assay for precision exceeded the $15 \%$ RSD (Table 3). When the precision testing was acceptable, the bias less then $\pm 15 \%$ was met for all analytes in all tested concentrations in both intra- and inter-day experiments (Table S4).

\section{Stability tests}

A stability test after three freeze and thaw cycles did not show statistically significant differences. There were also no significant differences found for a temperature stability test after leaving the sample for one day at room temperature, a 3-day post-preparative stability test for steroids after derivatization at room temperature, or for one-month stability test for the stock solutions of analytes. 


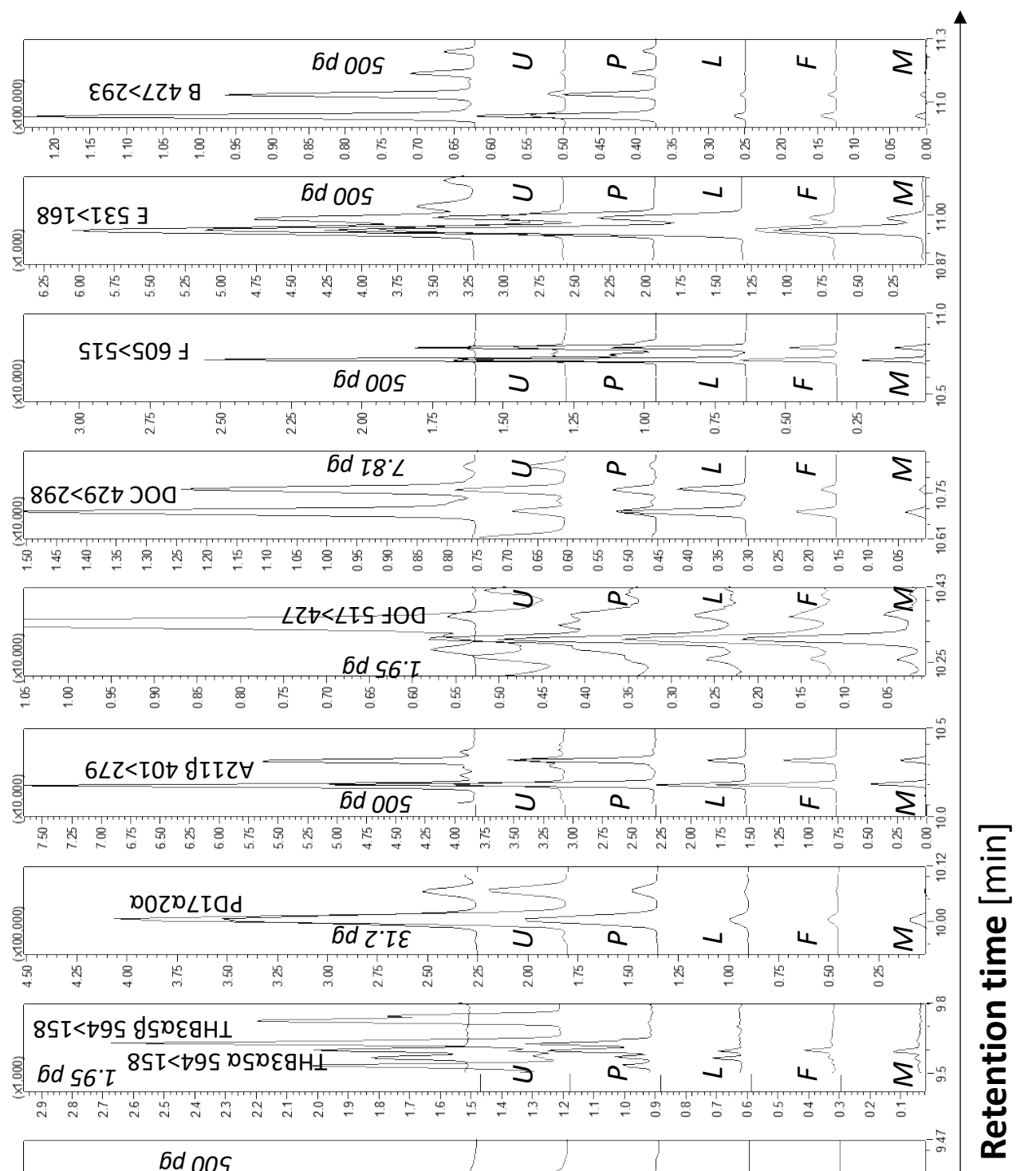

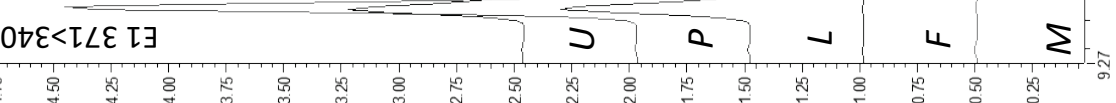

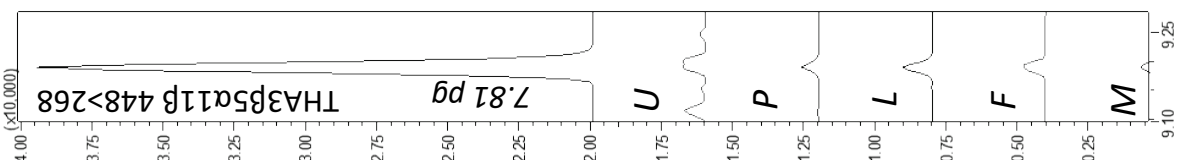

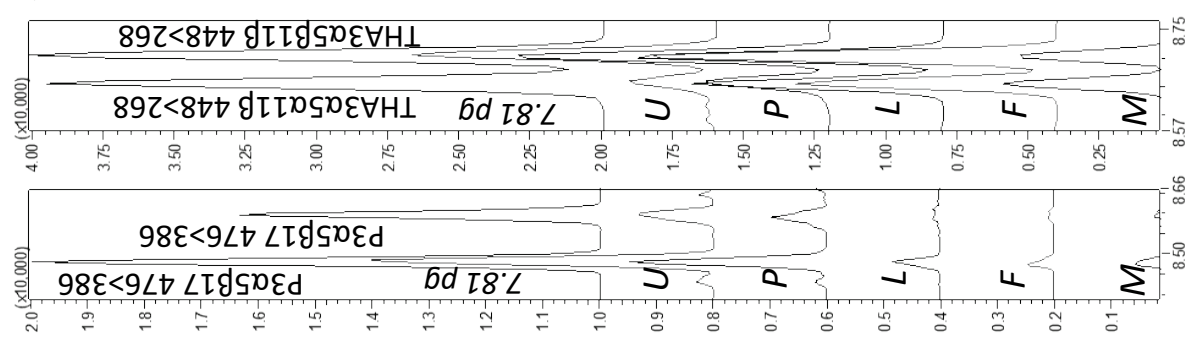

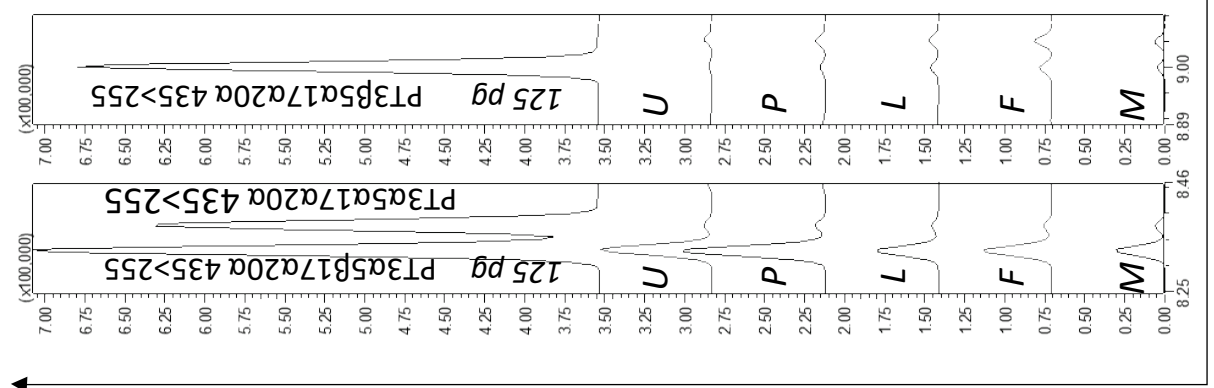




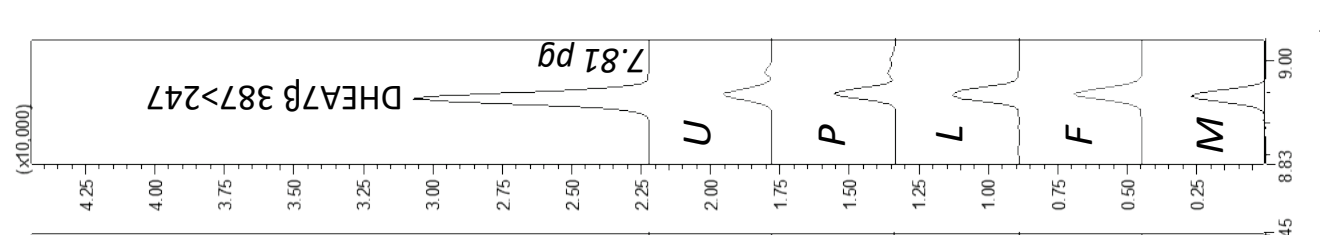

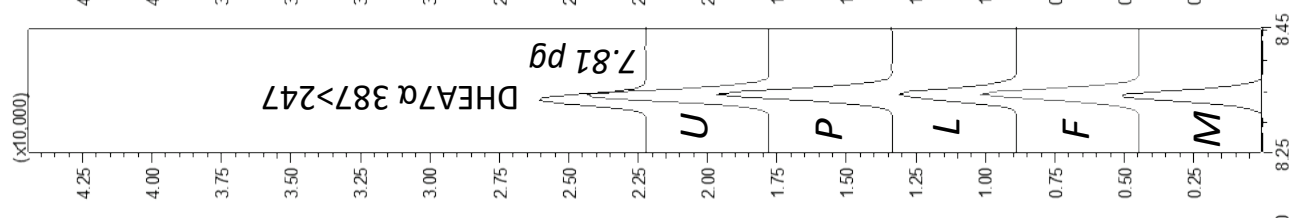

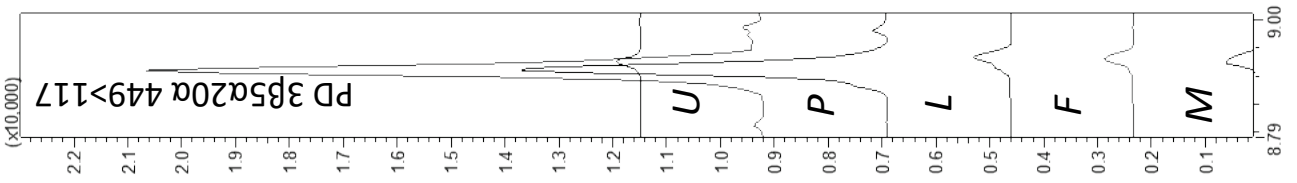
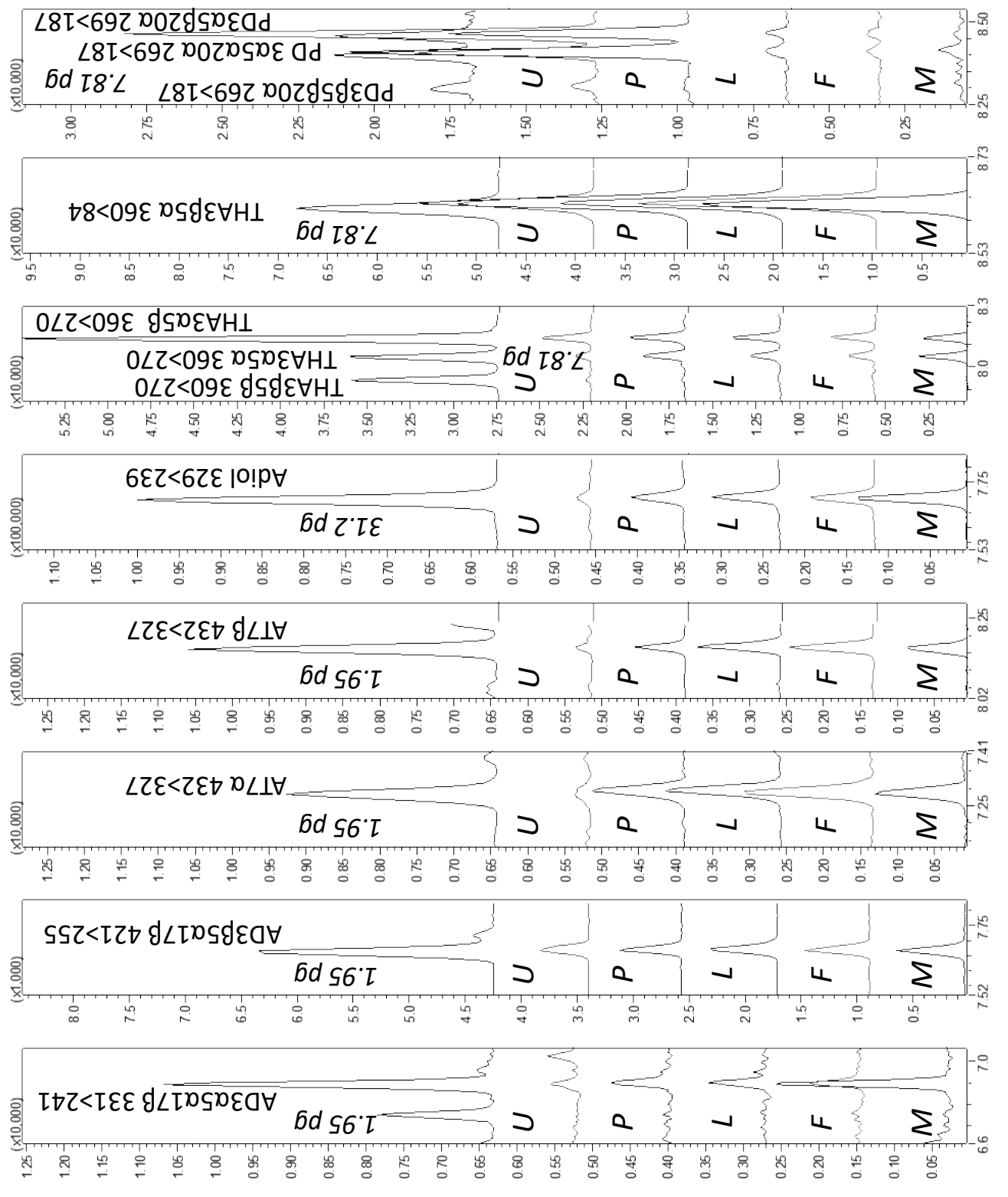

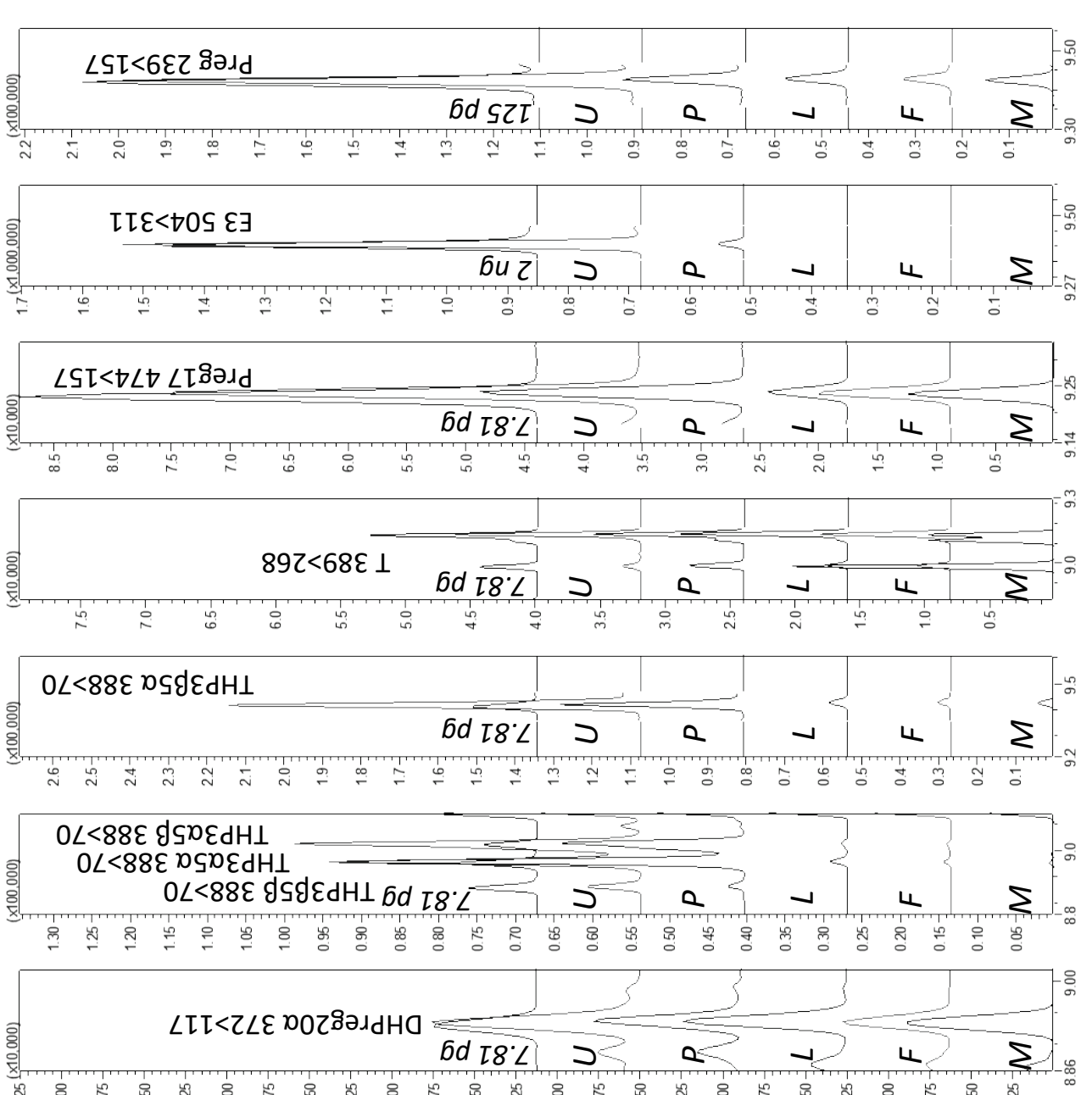

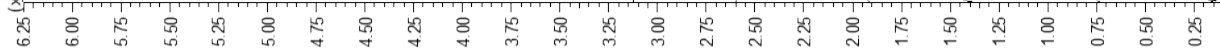

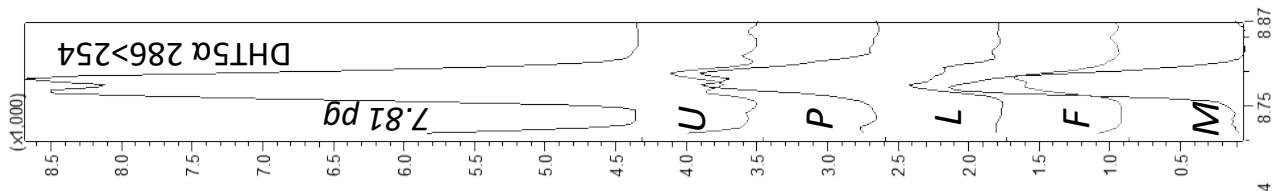

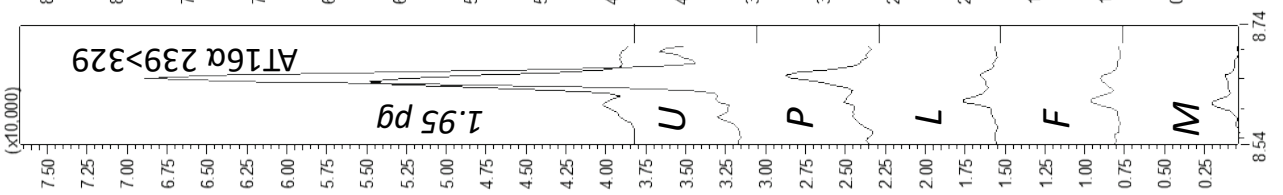

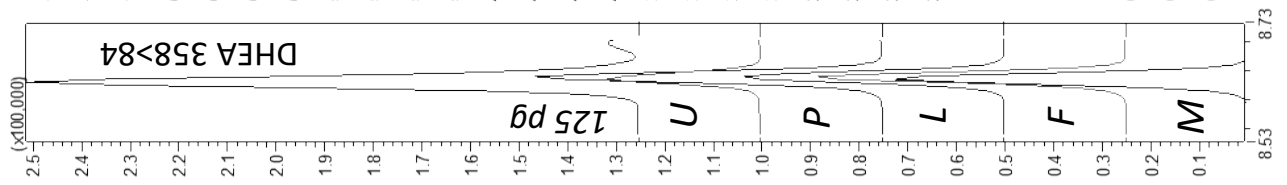

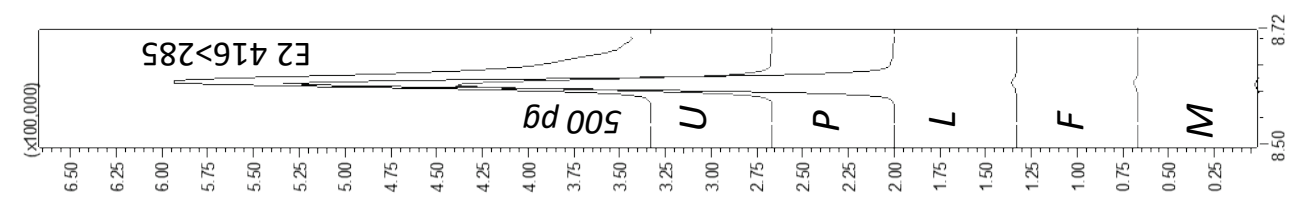




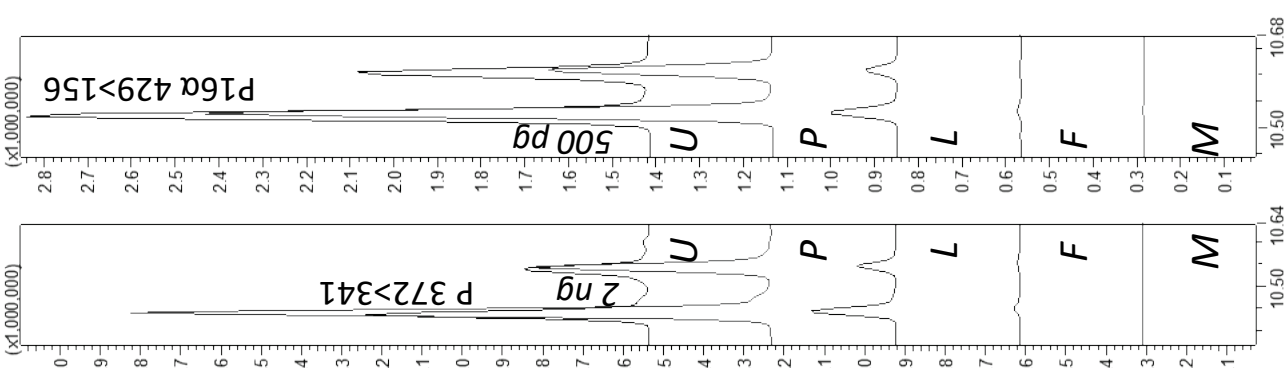

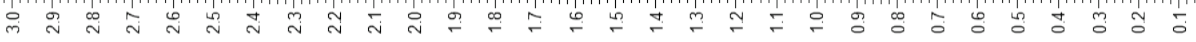

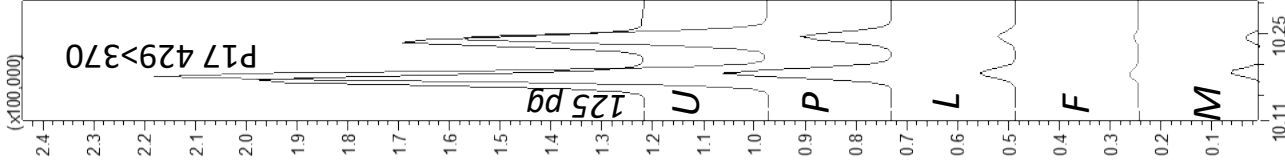

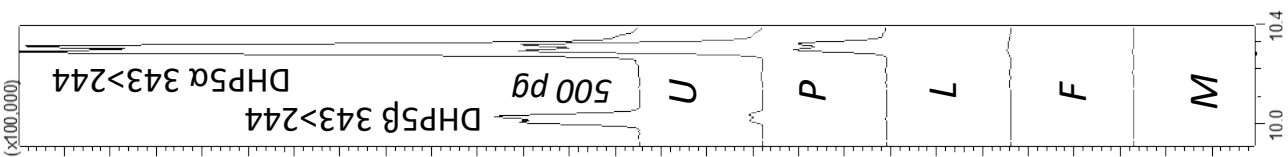

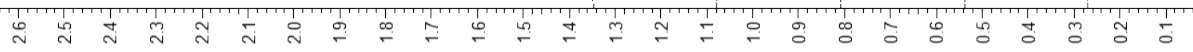

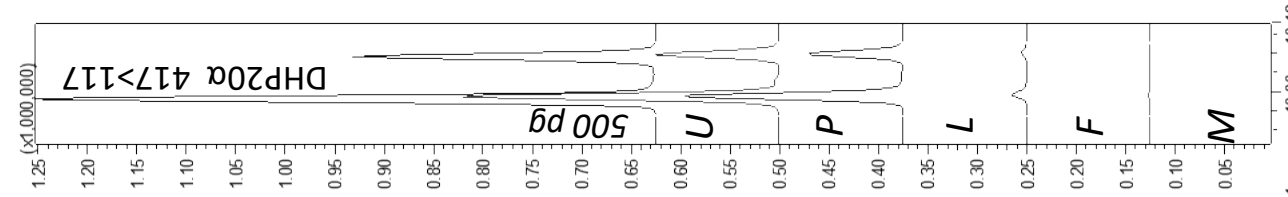

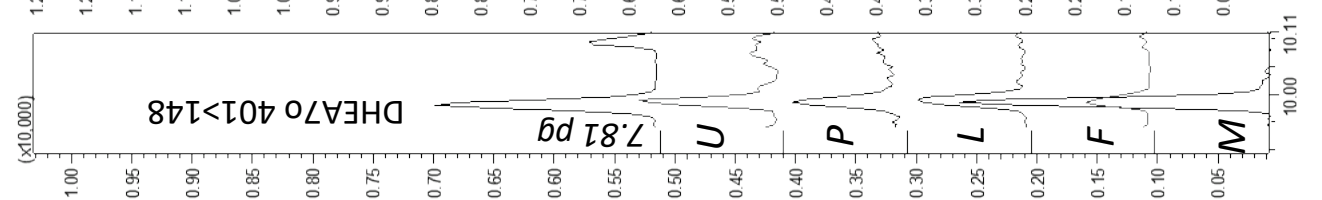

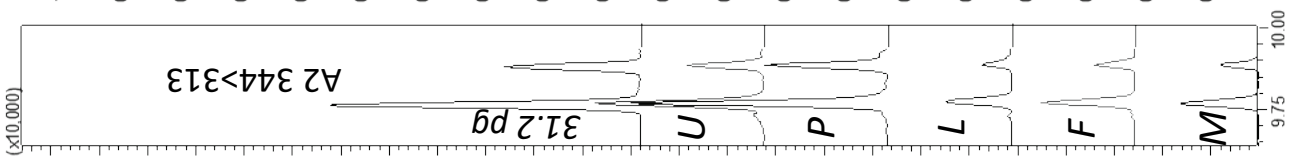

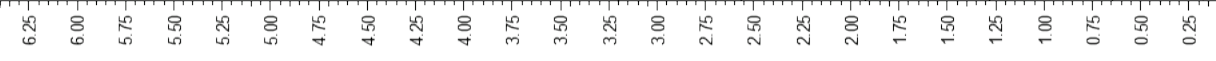

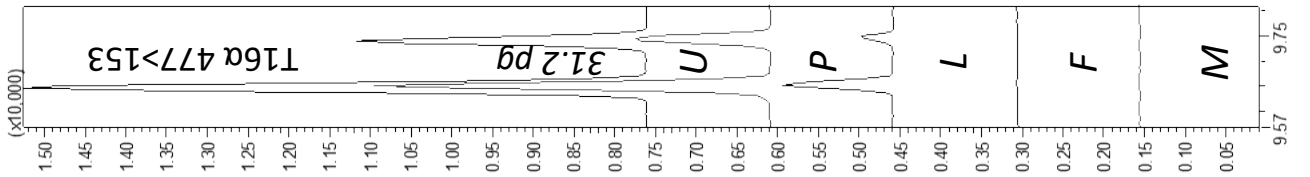

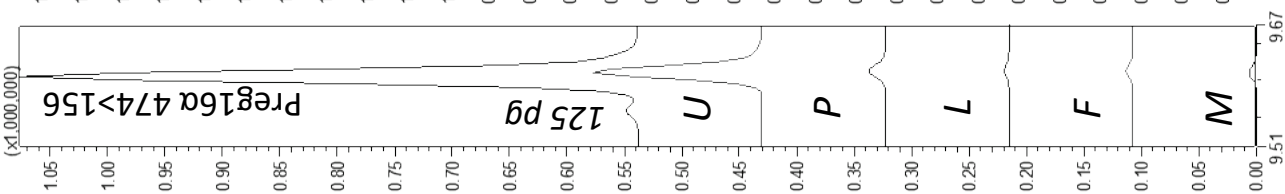
\&8<SIEDSHHO

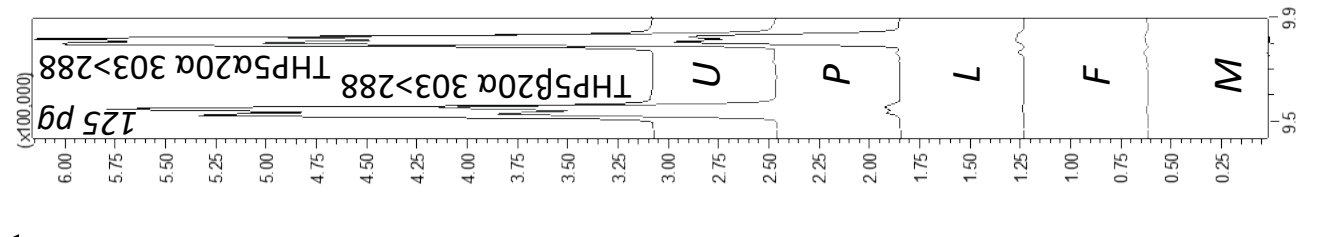




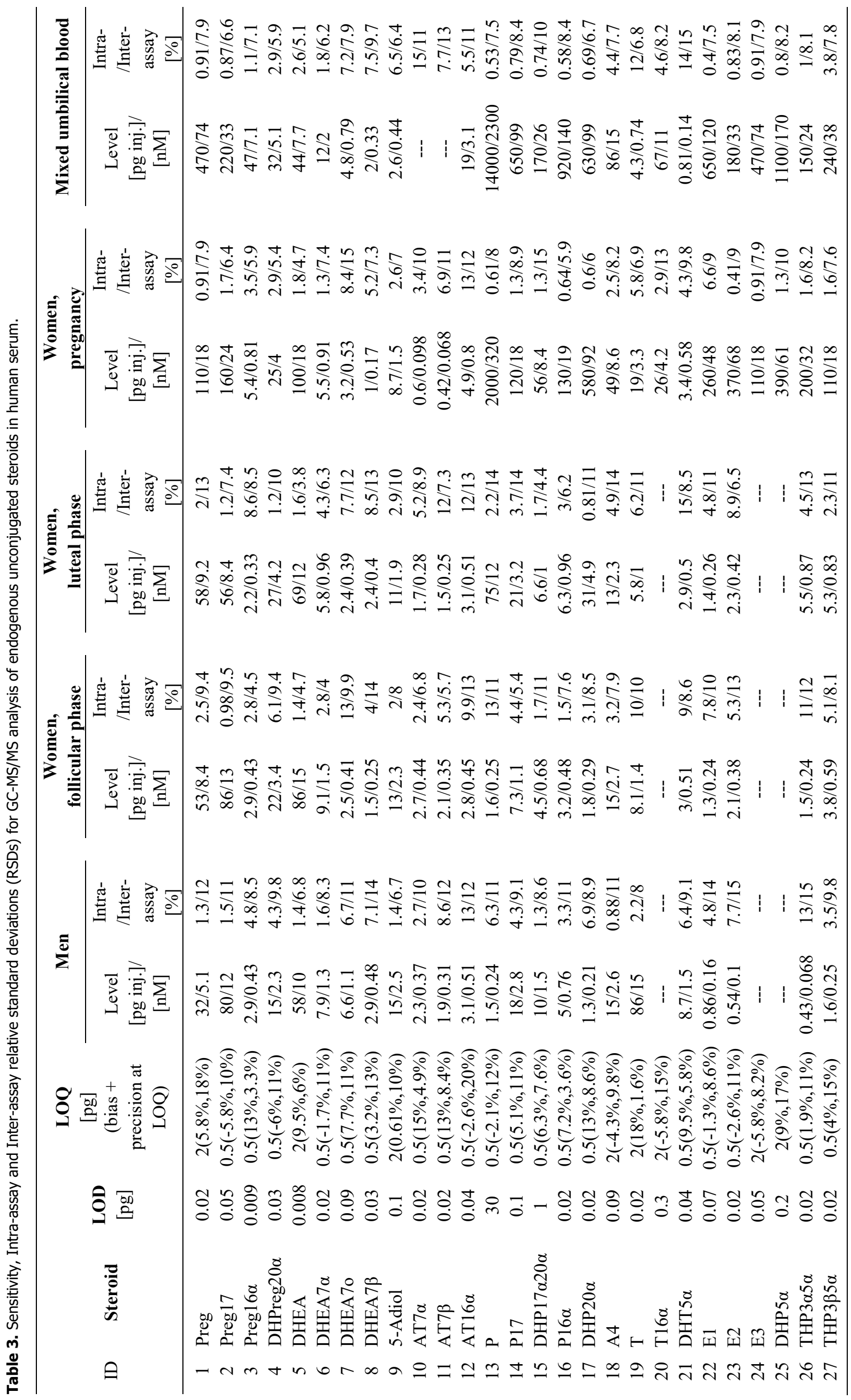




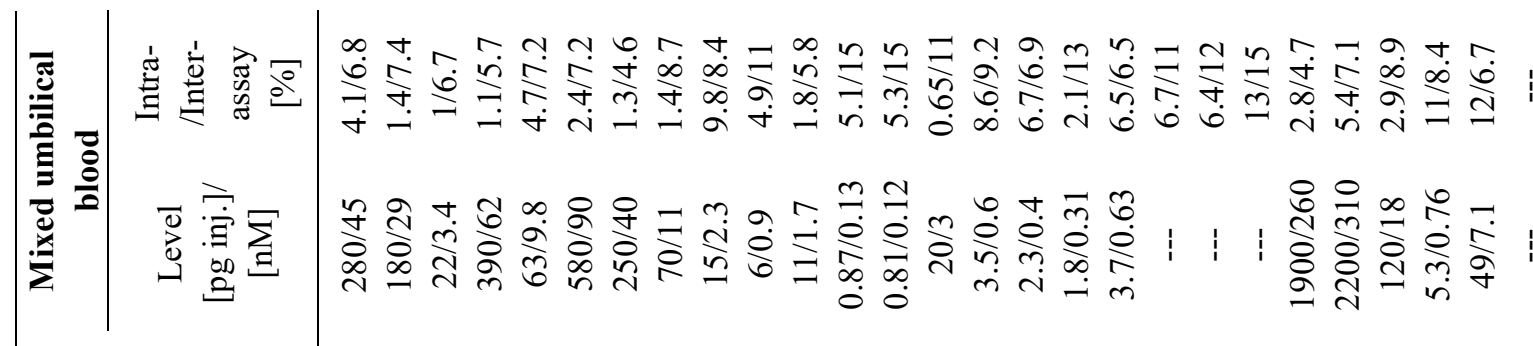

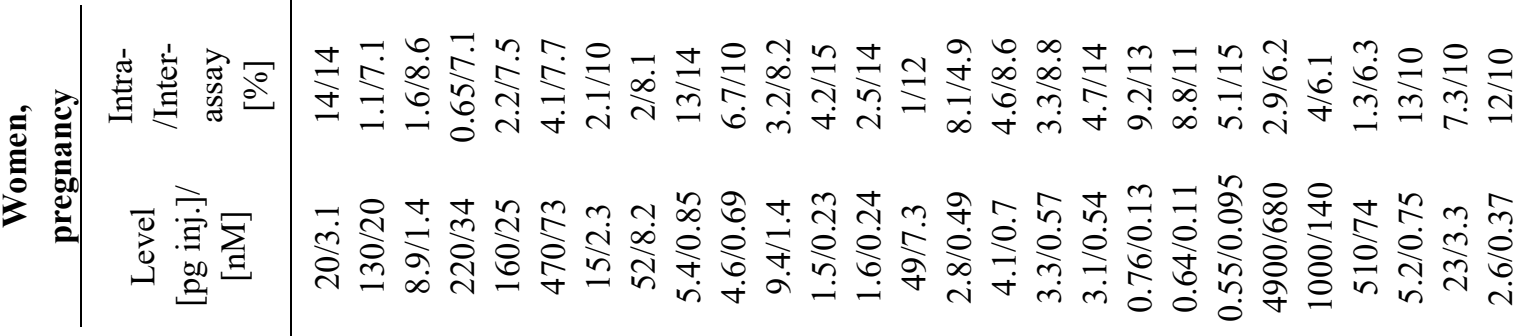

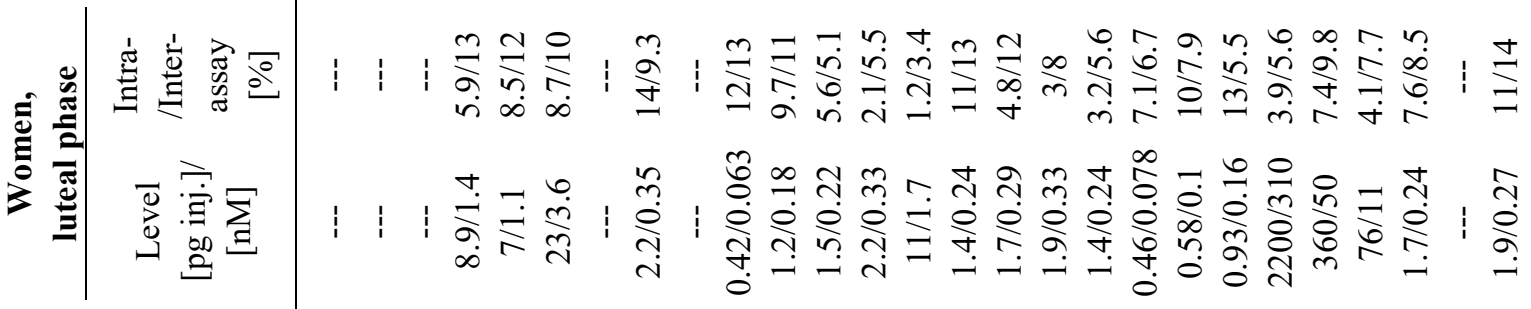

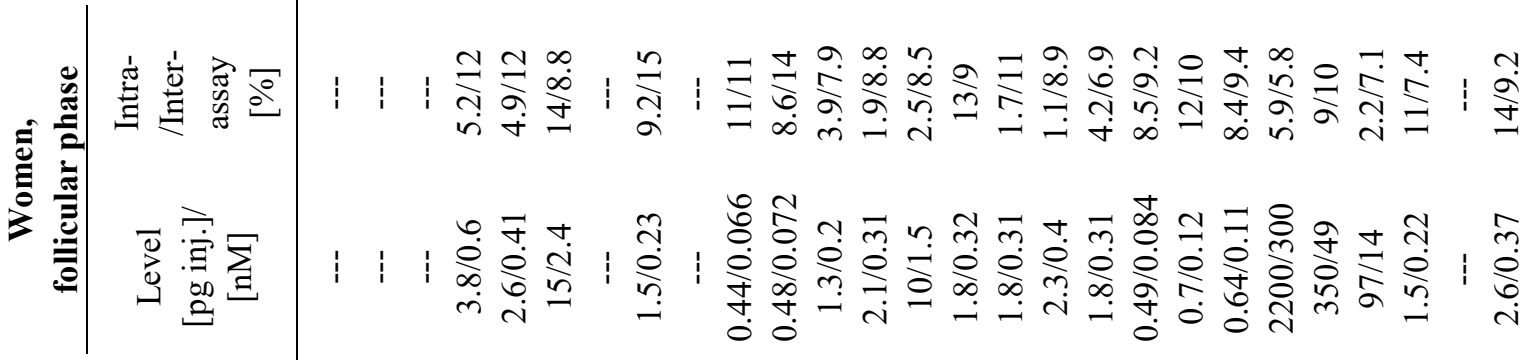

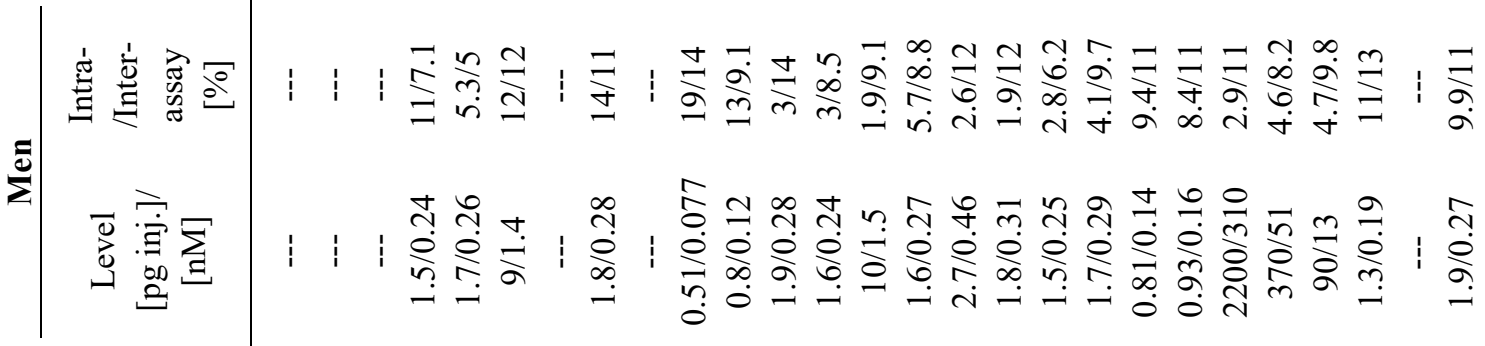

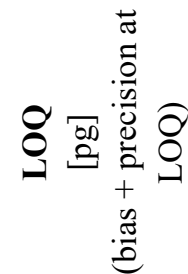

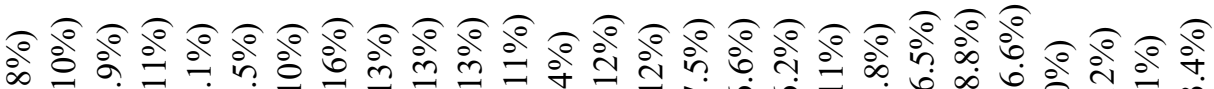

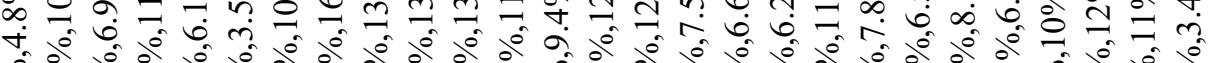

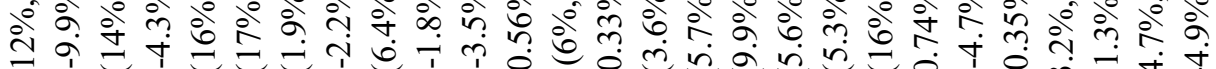

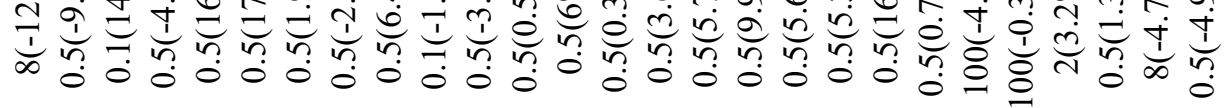

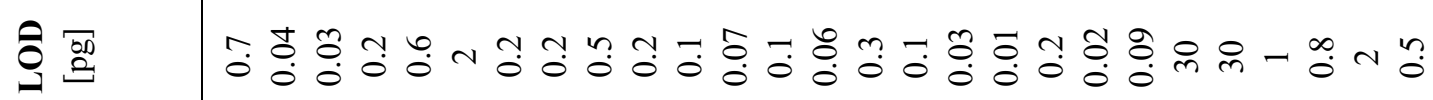

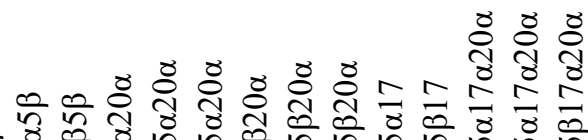
$\frac{n}{5} \frac{\infty}{5}$

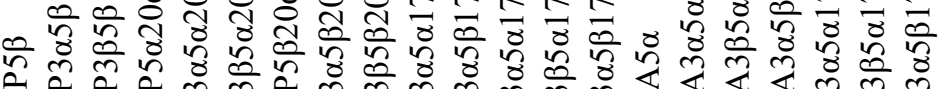

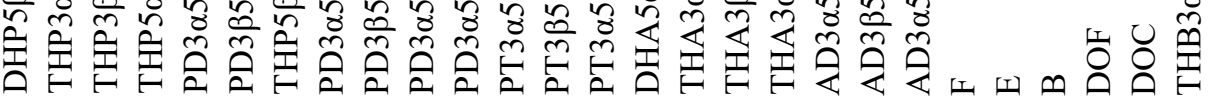

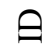

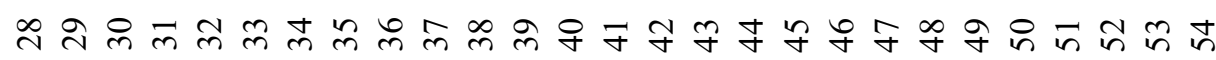




\begin{tabular}{|c|c|c|}
\hline | & 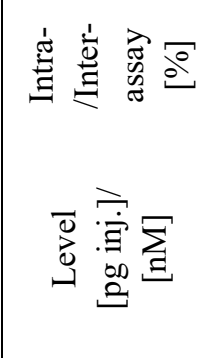 & 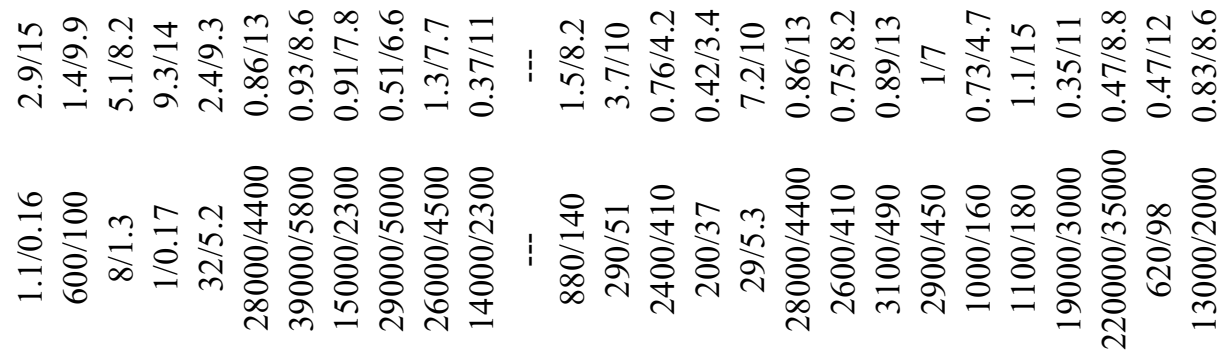 \\
\hline 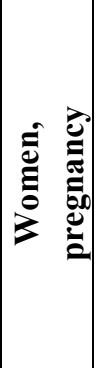 & 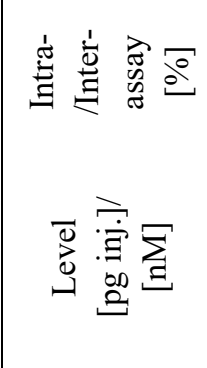 & 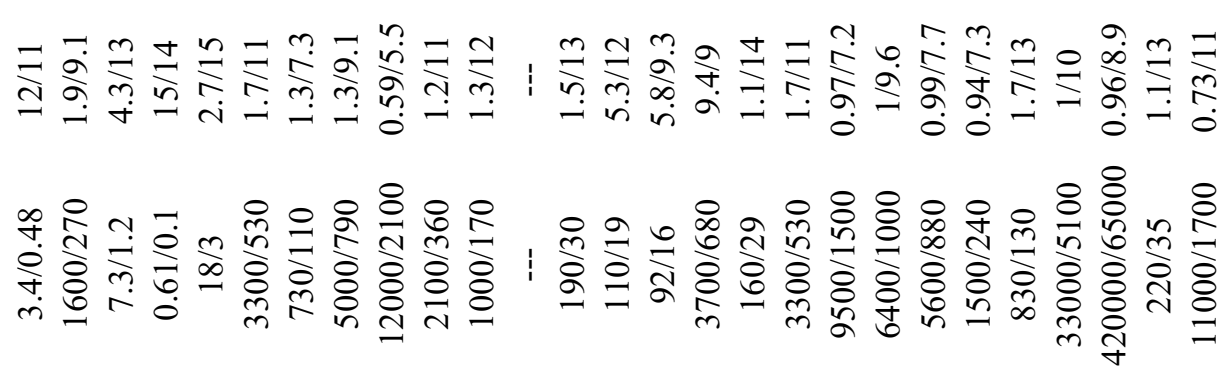 \\
\hline 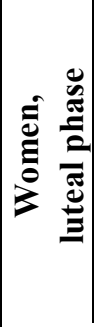 & 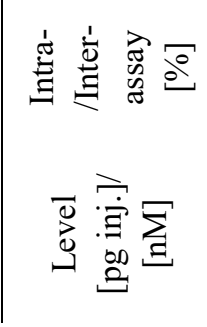 & 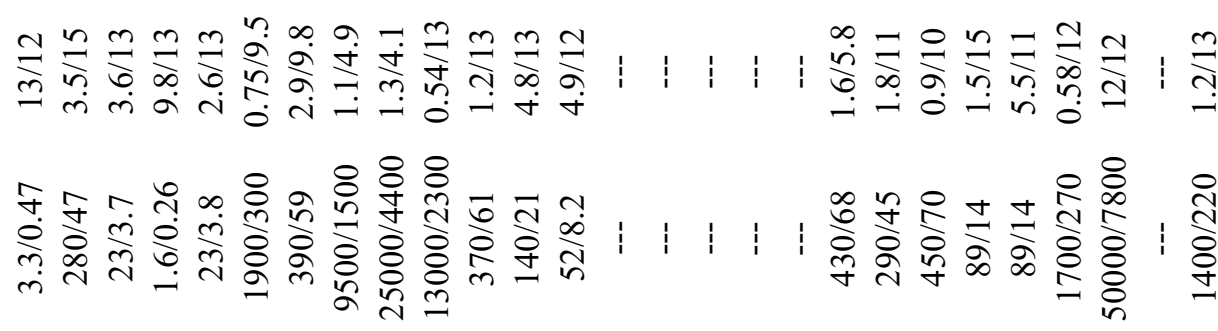 \\
\hline 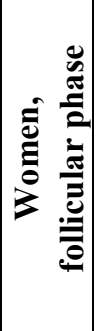 & 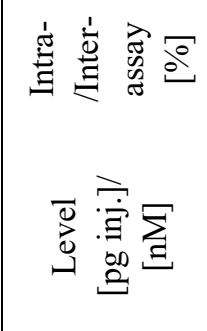 & 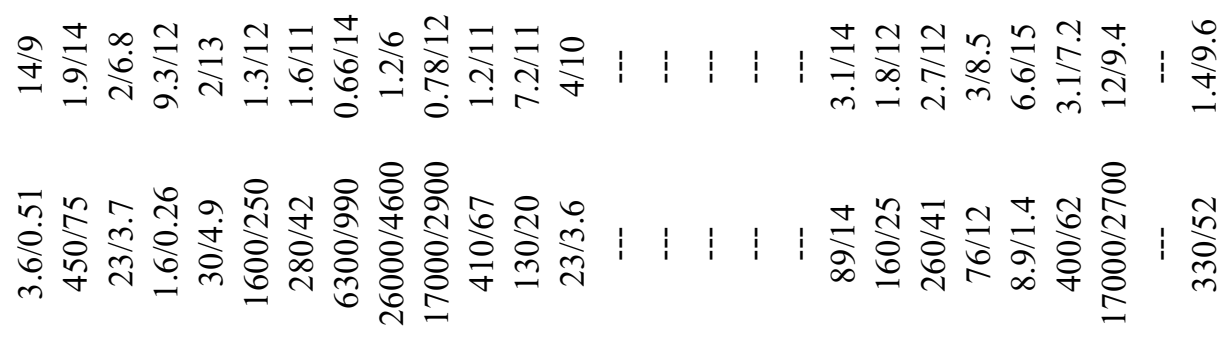 \\
\hline & 焉离怘 & 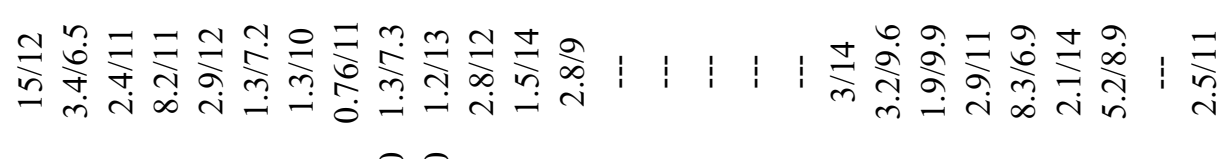 \\
\hline$=$ & 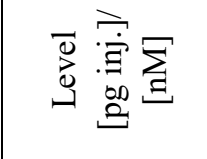 & 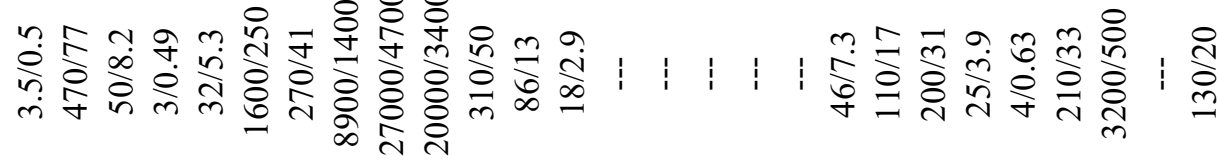 \\
\hline & 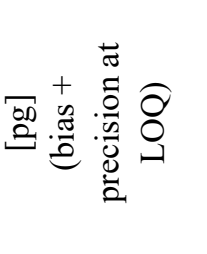 & 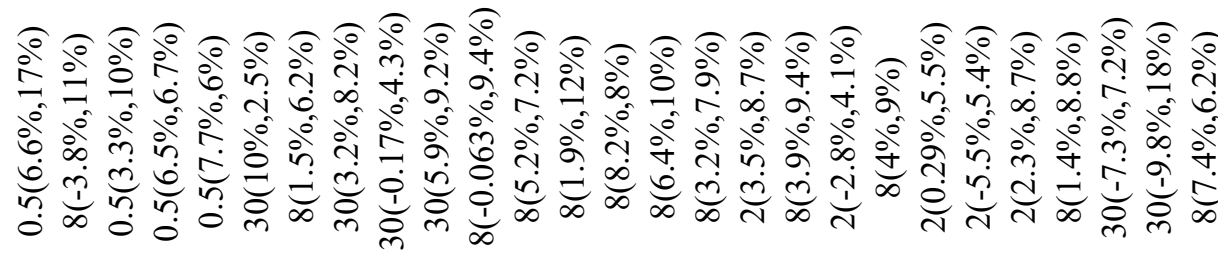 \\
\hline & రిత్తి & t. \\
\hline & 兽 & 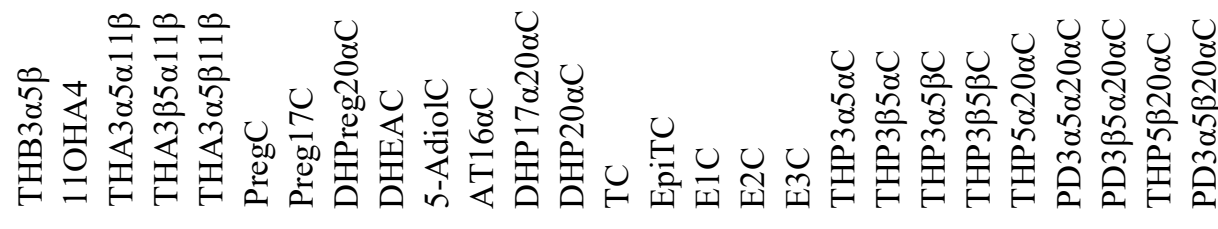 \\
\hline & & 86 \\
\hline
\end{tabular}




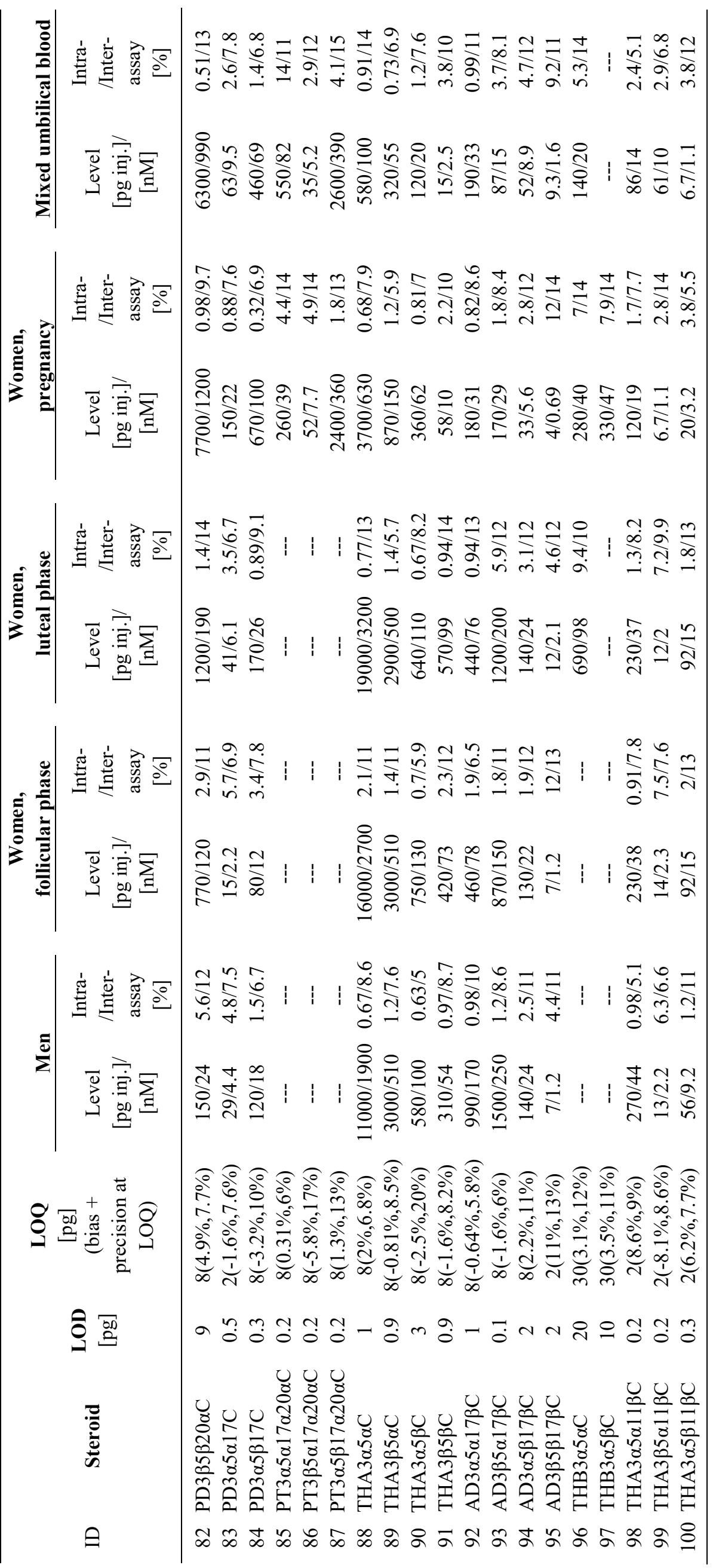




\section{Limit of detection and limit of quantification}

The lowest nonzero standard on the calibration curve defined the sensitivity. The analyte response at the LOQ was at least five times the analyte response of the zero calibrator and the bias at the LOQ was at most $\pm 20 \%$ of nominal concentration (as found using replicates prepared in six different runs). Similarly, the imprecision was at most $\pm 20 \%$ RSD as found using six replicates in four runs (Bioanalytical Method Validation 2018) (Table 3).

The LOD was sufficient in all cases where the intra- and/or inter-assay for precision did not exceeded the $15 \%$ RSD (Table 3 ) but the LOQ was borderline for the levels of $\mathrm{AD} 3 \alpha 5 \beta 17 \beta$ and $\mathrm{AD} 3 \alpha 5 \beta 17 \beta, \mathrm{E} 1$ and PD3 $\alpha 5 \beta 17$ levels in subjects out of pregnancy, and E2 and THP $3 \alpha 5 \alpha$ levels in men.

\section{Specificity/selectivity of the method}

In the co-eluting steroids, the selectivity was tested by injecting large amounts of the individual steroids and checking the potential contribution to other steroids respecting circulating levels of the potential interferents. For instance, for the transition $360>84$ between DHEA and epiandrosterone we found some interference. On the other hand, the interference of DHEA for transition $360>270$ in epiandrosterone was absent. Therefore, we choose the transition for quantitation of epiandrosterone $360>270$ instead of the $360>84$ transition. We also tested partly co-eluting pregnenolone and isopregnanolone and found some interference on $388>70$ but no interference on $388>173$ transition, which was then chosen for quantitation of isopregnanolone. The interferences were also tested for $388>70$ transition between partly co-eluting $7 \beta-\mathrm{OH}-$ DHEA and allopregnanolone but there was no perceptible interference. Some interference was found for $421>255$ transition between partly co-eluting 5 -androstene-3 $\beta, 17 \beta$ diol and $5 \alpha$-androstane-3$\beta, 17 \beta$-diol but the corresponding peaks only marginally coincided and the quantitation was possible. Besides the cases mentioned above and DOF, Preg16 $\alpha$, T16 $\alpha$, in which only a single MRM transition was recorded, no further perceptible interferences were found and the remaining ion ratios were within the tolerance according to WADA Technical Document TD2010IDCR "Identification Criteria for Qualitative Assays Incorporating Column Chromatography and Mass Spectrometry".

The levels of DOF were higher in male serum pool when compared with our previously published data from RIA assays (Hill et al. 1995), possibly due to the unintentional inclusion of patients with Cushing syndrome or congenital adrenal hyperplasia in some pooled samples. However, the recording of a single MRM transition for DOF did not rule out the possibility of some endogenous co-eluting interference being responsible of the apparent larger concentrations.

\section{Efficiency of methanolysis and stability of non-deuterated and deuterated steroids}

The deconjugating step in the present method was performed using the methanolysis according to Dehennin et al. (1996). This harsh acid hydrolysis is an adopted method of deconjugation that efficiently and rapidly cleaves both sulfates and glucuronides simultaneously. However, the formation of artefactual by-products is a known weakness of this method (Dehennin et al. 1996, Shackleton et al. 2004, Viljanto et al. 2018).

The results characterizing the efficiency of methanolysis for seven steroids sulfates/disulfates are summarized in Table S5. The efficiency of the methanolysis step for individual steroid sulfates was high, ranging from $85 \%$ to $116 \%(98 \pm 11 \%$, shown as mean \pm SD) (Table S5). Furthermore, we have tested the methanolysis efficiency for the DHEA sulfate using the same protocol but sulfated D6-DHEA as the internal standard. The efficiency of methanolysis step was close to absolute and almost the same when using the unconjugated or sulfated D6-DHEA as the internal standard (102.6 $\pm 0.9 \%$, shown as mean $\pm \mathrm{SD})$.

Considering the high efficiency of the methanolysis step, there is probably lessened necessity to use sulfated internal standards instead of the unconjugated ones as the deconjugation step does not represent a critical point in methanolysis. Thus, the more available unconjugated deuterated steroids may be used as satisfactory surrogates instead of their more appropriate conjugated equivalents. However, all internal standards (regardless their conjugation status) should possess isotopic stability in strongly acidic environment, which occurs during the methanolysis.

Some steroids have also limited chemical stability during the methanolysis (Dehennin et al. 1996, Viljanto et al. 2018). Dehennin et al. (1996) report, that while the sulfates of androsterone, epitestosterone, testosterone, 5-androstene-3 $\beta, 17 \beta$-diol (5-Adiol) and DHEA and glucuronides of androsterone and testosterone are almost totally recovered using the methanolysis, 
steroids with tertiary alcohol in the steroid 17 position and secondary alcohol in the steroid 11ß-position may dehydrate in strongly acidic conditions. This environment stimulates a protonation of the oxygen attached to steroid C-17 position and the nucleophilic attack by methanol, which consequently induces a cleavage of sulfate and glucuronide moieties on steroid molecules. However, there is also a risk of partial dehydration and formation of double bond (Viljanto et al. 2018).

The analysis of steroid chemical stability of unconjugated steroids (see section Efficiency of methanolysis and stability of non-deuterated and deuterated steroids) showed that most of them were relatively stable during the methanolysis. However, estrogens, 16 $\alpha$-hydroxy-metabolite of 5-Adiol and 11ß-hydroxy- and 3-oxo- steroids showed a limited stability (Table S6). Nevertheless, even in these cases, one can expect a similar degree of conversion to artefacts in standard and unknown samples on condition that they are processed in the same way in one run. So, the obtained results may be still acceptable as apparent in tables presenting analytical criteria for conjugated forms of steroids (see section Validation parameters). We are aware that the use of chemically and isotopically stable deuterated external standards with sufficient isotopic purity in conjugated forms would be a by far better approach.

The accessibility of appropriate deuterated conjugated internal standards is even more critical. Moreover, the deuterated internal standards are often isotopically unstable. The strongly acidic environment during the methanolysis promotes deuterium-hydrogen exchange, which considerably limits the number of applicable deuterated standards. For instance, a complete deuterium-hydrogen exchange was observed in a deuterium-labelled, D9-progesterone during methanolysis but no change was observed when the samples spiked with D9-progesterone were incubated with methanol in the neutral environment. The deuterium-hydrogen exchange is induced by acid-catalyzed enol tautomer formation when the double bond rapidly moves between the keto and enol forms. Although the equilibrium usually favors the ketotautomer, it can be shifted to the enol-one by acidic or alkaline environment. Steroids labelled on an $\alpha$-carbon adjacent to a ketone functional group(s) exhibit the hydrogen exchange, whereas other labelled analytes are unlikely to cause any problems. In extreme situations, such as in the case of D9-progesterone, the deuterium- hydrogen exchange via keto-enol tautomerism may lead to the formation of unlabeled product (Viljanto et al. 2018). We observed this effect during the methanolysis when using D9-progesterone and D8-17 $\alpha$ hydroxyprogesterone as internal standards. Besides the problems with the isotopic stability, the relatively frequent drawback of deuterated internal standards may be also their insufficient isotopic purity, which is specifically critical in analytes showing wide biological variability such as pregnane steroids exhibiting extreme changes during the menstrual cycle and pregnancy.

In contrast to some authors discriminating between glucuronide, monosulfate and disulfate moieties on steroid molecules, we did not test their levels separately (Mareck et al. 2008, Meng et al. 1997) but measured only the total polar conjugates. On one hand, the concurrent deconjugation of sulfates and glucuronides is a weakness of our method but on the other hand, the methanolysis is more robust and less laborious then the enzymatic hydrolysis or microcolumn pre-separation of sulfate, disulfate or glucuronide moieties from each other. Nevertheless, the discrimination between these moieties may be desirable in the diagnostics of some disorders such as the intrahepatic cholestasis of pregnancy. In this pathology, from a variety of pregnanediols, only the of $5 \alpha$-pregnane- $3 \alpha, 20 \alpha$-diol disulfate is considered as toxic for fetus (Abu-Hayyeh et al. 2013, Meng et al. 1997).

\section{Comparison of the present GC-MS/MS method with our previous GC-MS method}

Due to the high number of analytes and variety of steroids measured in human circulation, a comparison of all steroids with results from other methods was unachievable. Nevertheless, a number of our present results are comparable with those data from our previously published GC-MS method (Bicikova et al. 2013, Duskova et al. 2012, Hill et al. 2010b, Hill et al. 2011a, Hill et al. 2014, Hill et al. 2011b, Hill et al. 2010c, Kancheva et al. 2011, Majewska et al. 2014, Parizek et al. 2016, Paskova et al. 2014, Pospisilova et al. 2012, Vankova et al. 2016) as well as with the results of other authors (for review see Hill et al. 2010b).

The agreement between GC-MS, LC-MS/MS, RIA (for cortisol) and our present method for individual analytes mostly ranged from satisfactory to excellent results (Table S1 and Table S2, Fig. S1 and Fig. S2) even if there were little deviations from identity line and problems with LDR in two analytes. We compared responses to samples injected in high $(2 \mu \mathrm{l})$ and low 
$(0.2 \mu \mathrm{l})$ injection volumes for analytes with high circulating levels (some conjugated steroids) and found two of them, in which a considerable number of responses was not proportional to the injected volume (DHEA sulfate and androsterone sulfate). In these analytes, the samples from subjects with lower analyte circulating levels showed tight correlations between concentrations calculated from low and high injection volume and slopes (using the same calibration curve) of the corresponding regression lines did not significantly differ from 1. However, in the samples from subjects with higher analyte concentrations, the divergence between concentrations calculated for samples injected at high and low injection volume began to grow. Here the samples injected in low volume showed higher concentrations when compared with the same ones injected in the high volume (Fig. S3). It is evident that samples from subjects with higher analyte circulating levels underwent the same treatment as those from subject with the lower analyte circulating levels. Thus, the only cause of the differences in the former group should be the different injection volumes. As expected, the only change at lower injection volume was the shift of the analyte response to LDR in the samples from subjects with higher analyte circulating levels without significant influence on results in the samples from subject with the lower analyte circulating levels. These levels evidently remained sufficiently high for analysis at lower injection volumes. Based on these data, the sulfates of DHEA and androsterone were measured at low injection volumes of samples in the present method and the method validation for these steroid conjugated was also completed at low injection volumes.

In addition to the steroids quantified in the previous method (Hill et al. 2010b), the present one was extended for corticoids, 11 $\beta$-hydroxy-androstanes and $17 \alpha$-hydroxylated $5 \alpha / \beta$-reduced pregnanes. The lastmentioned substances may be useful for the investigation of the alternative "backdoor" pathway. When comparing the analytical characteristics of the present and previous methods, the first exhibited by far higher selectivity, generally higher sensitivity and better precision particularly for $17 \alpha$-hydroxysteroids. However, in the case of estrogens the precision was worse and even unsatisfactory for estrone in non-pregnant subjects, which may be associated with the use of different derivatization agent in the silylation step and worse repeatability (during the drying of derivatized mixture under nitrogen because to its higher heterogeneity in comparison with our previous method). On the other hand, the more intense and lengthier derivatization together with the use of more advanced GC-MS/MS platform resulted in substantially improved sensitivity and precision in $17 \alpha$-hydroxy-steroids and enabled the quantification of corticoids and 11ß-hydroxy-androgens, which were undetectable by our previous method.

\section{Limitations of our method}

We acknowledge that our proposed method has some limitations. The first is the absence of conjugated external and deuterated internal standards in most conjugated steroids and absence of deuterated internal standards even for most unconjugated steroids. The first reason was a limited accessibility of these substances. The further serious problem especially in quantification of conjugated steroids was chemical and isotopic instability as well as isotopic impurity of various deuterated standards (as discussed above). Therefore, we excluded the analysis of four steroid conjugates, which were well detectable but extremely instable during the hydrolysis such as conjugated $7 \alpha / \beta$-hydroxy-metabolites of DHEA and 5-Adiol. The difficult accessibility, isotopic and chemical instability were also the reasons for which we used only a single (but pure and stable) deuterated steroid conjugate (D6-DHEA sulfate) as the internal standard for the quantification of conjugated steroids.

Furthermore, in spite of wide spectrum of the measured steroids some diagnostically important steroids remained, which were not included. Partly due to unfavorable fragmentation pattern of the steroid even after derivatization resulting in low sensitivity as in the case of 11-deoxycortisol. In addition, 11-deoxycorticosterone was below the LOQ for non-pregnant subjects and 21-deoxycortisol was above the LOQ for all groups but the sensitivity was also relatively low. Also, the sensitivity for estrogens in non-pregnant subjects was low. The quantification of interesting steroids such as $11 \beta$-hydroxy-testosterone, 11-oxo-testosterone and 11-oxo-androstenedione was not tested as well as the measurement of steroid $6 \alpha / \beta$-hydroxy-catabolites.

\section{Conclusions}

To the best of our knowledge, in spite of the limitations described above, this is the first GC-MS/MS method for multicomponent quantitation of circulating 
steroids validated for different physiological conditions in humans including gender differences and pregnancy status. In addition, this method currently includes the largest spectrum of human circulating steroids and steroid polar conjugates, at least for the GC-MS/MS platform. As have been demonstrated in our previous papers, steroid profiling enables various pathologies to be rapidly diagnosed (Bicikova et al. 2013, Hill et al. 2010c, Kanceva et al. 2015, Parizek et al. 2016, Sosvorova et al. 2015, Vankova et al. 2016). The present GC-MS/MS method includes a wide range of analytes, which reflect activities of most steroidogenic enzymes. Thus, it could be used for the estimation of changes in steroidogenesis for various physiological and pathophysiological situations and subsequently the data obtained can be utilized for uncovering the mechanisms of some steroidrelated human pathologies (Parizek et al. 2016, Sterzl et al. 2017, Vankova et al. 2016).

Nevertheless, the hydrolysis step is laborious and may carry problems with stability of some steroid conjugates. Furthermore, some positions of sulfate or glucuronide groups in steroid molecule may be resistant to hydrolysis although the deconjugation step used in the present method appears to be quite efficient. Moreover, the physiological and pathophysiological importance of steroid sulfates and glucuronides may be different. Therefore, the future work in steroid assay development should strive to measure the entire conjugated molecule without hydrolysis.

\section{Conflict of Interest}

There is no conflict of interest.

\section{Acknowledgements}

This study was supported by grants 160415 from the Grant Agency of Charles University in Prague (GAUK), NV17-30528A from the Czech Health Research Council (AZV ČR) "Prediction of Gestational Diabetes on the Basis of Steroid Metabolism", OPPR CZ.07.1.02/0.0/0.0/16_040/0000381 "Software devices for estimation of predisposition to liver problems in pregnancy and for their detection" and OPPK CZ.2.16/3.1.00/21518 "Equipment for metabolomics research".

\section{References}

ABU-HAYYEH S, PAPACLEOVOULOU G, LOVGREN-SANDBLOM A, TAHIR M, ODUWOLE O, JAMALUDIN NA, RAVAT S, NIKOLOVA V, CHAMBERS J, SELDEN C, REES M, MARSCHALL HU, PARKER MG, WILLIAMSON C: Intrahepatic cholestasis of pregnancy levels of sulfated progesterone metabolites inhibit farnesoid X receptor resulting in a cholestatic phenotype. Hepatology 57: 716-726, 2013.

ANDRASI N, MOLNAR B, DOBOS B, VASANITS-ZSIGRAI A, ZARAY G, MOLNAR-PERL I: Determination of steroids in the dissolved and in the suspended phases of wastewater and Danube River samples by gas chromatography, tandem mass spectrometry. Talanta 115: 367-373, 2013.

BICIKOVA M, HILL M, RIPOVA D, MOHR P, HAMPL R: Determination of steroid metabolome as a possible tool for laboratory diagnosis of schizophrenia. J Steroid Biochem Mol Biol 133: 77-83, 2013.

BIOANALYTICAL METHOD VALIDATION. Guidance for Industry. BIOPHARMACEUTICS (ed.), 2018.

BLAND JM, ALTMAN DG: Statistical methods for assessing agreement between two methods of clinical measurement. Lancet 1: 307-310, 1986.

BLOKLAND MH, VAN TRICHT EF, VAN ROSSUM HJ, STERK SS, NIELEN MW: Endogenous steroid profiling by gas chromatography-tandem mass spectrometry and multivariate statistics for the detection of natural hormone abuse in cattle. Food Addit Contam Part A Chem Anal Control Expo Risk Assess 29: 1030-1045, 2012.

BROCHU M, BELANGER A: Comparative study of plasma steroid and steroid glucuronide levels in normal men and in men with benign prostatic hyperplasia. Prostate 11: 33-40, 1987.

BROCHU M, BELANGER A, DUPONT A, CUSAN L, LABRIE F: Effects of flutamide and aminoglutethimide on plasma 5 alpha-reduced steroid glucuronide concentrations in castrated patients with cancer of the prostate. J Steroid Biochem 28: 619-622, 1987.

CHOI MH, CHUNG BC: Diagnostic evaluation of enzyme activity related to steroid metabolism by mass spectrometrybased steroid profiling. Mass Spectrometry Letters 5: 35-41, 2014. 
CHRISTAKOUDI S, COWAN DA, TAYLOR NF: Steroids excreted in urine by neonates with 21-hydroxylase deficiency: characterization, using GC-MS and GC-MS/MS, of the D-ring and side chain structure of pregnanes and pregnenes. Steroids 75: 34-52, 2010.

CHRISTAKOUDI S, COWAN DA, TAYLOR NF: Steroids excreted in urine by neonates with 21-hydroxylase deficiency. 2. Characterization, using GC-MS and GC-MS/MS, of pregnanes and pregnenes with an oxo- group on the A- or B-ring. Steroids 77: 382-393, 2012a.

CHRISTAKOUDI S, COWAN DA, TAYLOR NF: Steroids excreted in urine by neonates with 21-hydroxylase deficiency. 3. Characterization, using GC-MS and GC-MS/MS, of androstanes and androstenes. Steroids 77: 1487-1501, 2012b.

CHRISTAKOUDI S, COWAN DA, TAYLOR NF: Steroids excreted in urine by neonates with 21-hydroxylase deficiency. 4. Characterization, using GC-MS and GC-MS/MS, of 11oxo-pregnanes and 11oxo-pregnenes. Steroids 78: 468-475, 2013.

COURANT F, AKSGLAEDE L, ANTIGNAC JP, MONTEAU F, SORENSEN K, ANDERSSON AM, SKAKKEBAEK NE, JUUL A, BIZEC BL: Assessment of circulating sex steroid levels in prepubertal and pubertal boys and girls by a novel ultrasensitive gas chromatography-tandem mass spectrometry method. $J$ Clin Endocrinol Metab 95: 82-92, 2010.

DEHENNIN L, PERES G: Plasma and urinary markers of oral testosterone misuse by healthy men in presence of masking epitestosterone administration. Int J Sports Med 17: 315-319, 1996.

DEHENNIN L, LAFARGE P, DAILLY P, BAILLOUX D, LAFARGE JP: Combined profile of androgen glucuro- and sulfoconjugates in post-competition urine of sportsmen: a simple screening procedure using gas chromatography-mass spectrometry. J Chromatogr B Biomed Appl 687: 85-91, 1996.

DUSKOVA M, SIMUNKOVA K, HILL M, VELIKOVA M, KUBATOVA J, KANCHEVA L, KAZIHNITKOVA H, HRUSKOVICOVA H, POSPISILOVA H, RACZ B, SALATOVA M, CIRMANOVA V, KRALIKOVA E, STARKA L, PARIZEK A: Chronic cigarette smoking alters circulating sex hormones and neuroactive steroids in premenopausal women. Physiol Res 61: 97-111, 2012.

ESQUiVEL A, POZO OJ, GARROSTAS L, BALCELlS G, GOMEZ C, KOTRONOULAS A, JOGLAR J, VENTURA R: LC-MS/MS detection of unaltered glucuronoconjugated metabolites of metandienone. Drug Test Anal 9: 534-544, 2017.

GAMBELUNGHE C, SOMMAVILLA M, FERRANTI C, ROSSI R, ARONI K, MANES N, BACCI M: Analysis of anabolic steroids in hair by GC/MS/MS. Biomed Chromatogr 21: 369-375, 2007.

GOMES RL, MEREDITH W, SNAPE CE, SEPHTON MA: Conjugated steroids: analytical approaches and applications. Anal Bioanal Chem 393: 453-458, 2009.

HA YW, MOON JY, JUNG HJ, CHUNG BC, CHOI MH: Evaluation of plasma enzyme activities using gas chromatography-mass spectrometry based steroid signatures. J Chromatogr B Analyt Technol Biomed Life Sci 877: 4125-4132, 2009.

HANEEF J, SHAHARYAR M, HUSAIN A, RASHID M, MISHRA R, PARVEEN S, AHMED N, PAL M, KUMAR D: Application of LC-MS/MS for quantitative analysis of glucocorticoids and stimulants in biological fluids. J Pharm Anal 3: 341-348, 2013.

HANSEN M, JACOBSEN NW, NIELSEN FK, BJORKLUND E, STYRISHAVE B, HALLING-SORENSEN B: Determination of steroid hormones in blood by GC-MS/MS. Anal Bioanal Chem 400: 3409-3417, 2011.

HILL M, LAPCIK O, HAMPL R, STARKA L, PUTZ Z: Radioimmunoassay of three deoxycorticoids in human plasma following HPLC separation. Steroids 60: 615-620, 1995.

HILL M, PARIZEK A, CIBULA D, KANCHEVA R, JIRASEK JE, JIRKOVSKA M, VELIKOVA M, KUBATOVA J, KLIMKOVA M, PASKOVA A, ZIZKA Z, KANCHEVA L, KAZIHNITKOVA H, ZAMRAZILOVA L, STARKA L: Steroid metabolome in fetal and maternal body fluids in human late pregnancy. $J$ Steroid Biochem Mol Biol 122: 114-132, 2010a.

HILL M, PARIZEK A, KANCHEVA R, DUSKOVA M, VELIKOVA M, KRIZ L, KLIMKOVA M, PASKOVA A, ZIZKA Z, MATUCHA P, MELOUN M, STARKA L: Steroid metabolome in plasma from the umbilical artery, umbilical vein, maternal cubital vein and in amniotic fluid in normal and preterm labor. J Steroid Biochem Mol Biol 121: 594-610, 2010b. 
HILL M, ZARUBOVA J, MARUSIC P, VRBIKOVA J, VELIKOVA M, KANCHEVA R, KANCHEVA L, KUBATOVA J, DUSKOVA M, ZAMRAZILOVA L, KAZIHNITKOVA H, SIMUNKOVA K, STARKA L: Effects of valproate and carbamazepine monotherapy on neuroactive steroids, their precursors and metabolites in adult men with epilepsy. J Steroid Biochem Mol Biol 122: 239-252, 2010c.

HILL M, PARIZEK A, VELIKOVA M, KUBATOVA J, KANCHEVA R, DUSKOVA M, SIMUNKOVA K, KLIMKOVA M, PASKOVA A, ZIZKA Z, JIRASEK JE, JIRKOVSKA M, STARKA L: The distribution of placental oxidoreductase isoforms provides different milieus of steroids influencing pregnancy in the maternal and fetal compartment. Horm Mol Biol Clin Invest 4: 581-600, 2011a.

HILL M, VRBIKOVA J, ZARUBOVA J, KANCHEVA R, VELIKOVA M, KANCHEVA L, KUBATOVA J, DUSKOVA M, MARUSIC P, PARIZEK A, STARKA L: The steroid metabolome in lamotrigine-treated women with epilepsy. Steroids 76: 1351-1357, 2011 b.

HILL M, PASKOVA A, KANCEVA R, VELIKOVA M, KUBATOVA J, KANCHEVA L, ADAMCOVA K, MIKESOVA M, ZIZKA Z, KOUCKY M, SARAPATKOVA H, KACER V, MATUCHA P, MELOUN M, PARIZEK A: Steroid profiling in pregnancy: a focus on the human fetus. $J$ Steroid Biochem Mol Biol 139: 201-222, 2014.

IMPENS S, VAN LOCO J, DEGROODT JM, DE BRABANDER H: A downscaled multi-residue strategy for detection of anabolic steroids in bovine urine using gas chromatography tandem mass spectrometry (GC-MS3). Anal Chim Acta 586: 43-48, 2007.

KANCEVA R, STARKA L, KANCHEVA L, HILL M, VELIKOVA M, HAVRDOVA E: Increased serum levels of C21 steroids in female patients with multiple sclerosis. Physiol Res 64 (Suppl 2): S247-S254, 2015.

KANCHEVA R, HILL M, NOVAK Z, CHRASTINA J, KANCHEVA L, STARKA L: Neuroactive steroids in periphery and cerebrospinal fluid. Neuroscience 191: 22-27, 2011.

KELLY C: Analysis of steroids in environmental water samples using solid-phase extraction and ion-trap gas chromatography-mass spectrometry and gas chromatography-tandem mass spectrometry. J Chromatogr A 872: 309-314, 2000.

KIM B, MOON JY, CHOI MH, YANG HH, LEE S, LIM KS, YOON SH, YU KS, JANG IJ, CHO JY: Global metabolomics and targeted steroid profiling reveal that rifampin, a strong human PXR activator, alters endogenous urinary steroid markers. J Proteome Res 12: 1359-1368, 2013.

KRONE N, HUGHES BA, LAVERY GG, STEWART PM, ARLT W, SHACKLETON CH: Gas chromatography/mass spectrometry (GC/MS) remains a pre-eminent discovery tool in clinical steroid investigations even in the era of fast liquid chromatography tandem mass spectrometry (LC/MS/MS). J Steroid Biochem Mol Biol 121: 496-504, 2010.

KURECKOVA K, MARALIKOVA B, VENTURA K: Supercritical fluid extraction of steroids from biological samples and first experience with solid-phase microextraction-liquid chromatography. J Chromatogr B Analyt Technol Biomed Life Sci 770: 83-89, 2002.

LABRIE F, BELANGER A, CUSAN L, GOMEZ JL, CANDAS B: Marked decline in serum concentrations of adrenal C19 sex steroid precursors and conjugated androgen metabolites during aging. J Clin Endocrinol Metab 82: 2396-2402, 1997.

MAJEWSKA MD, HILL M, URBANOWICZ E, ROK-BUJKO P, BIENKOWSKI P, NAMYSLOWSKA I, MIERZEJEWSKI P: Marked elevation of adrenal steroids, especially androgens, in saliva of prepubertal autistic children. Eur Child Adolesc Psychiatry 23: 485-498, 2014.

MANUILOVA E, SCHUETZENMEISTER A, MODEL F: Method Comparison Regression. https://CRAN.R-project.org/package=mcr, 2014.

MARCOS J, PASCUAL JA, DE LA TORRE X, SEGURA J: Fast screening of anabolic steroids and other banned doping substances in human urine by gas chromatography/tandem mass spectrometry. J Mass Spectrom 37: 1059-1073, 2002.

MARCOS J, RENAU N, CASALS G, SEGURA J, VENTURA R, POZO OJ: Investigation of endogenous corticosteroids profiles in human urine based on liquid chromatography tandem mass spectrometry. Anal Chim Acta 812: 92-104, 2014. 
MARECK U, GEYER H, OPFERMANN G, THEVIS M, SCHANZER W: Factors influencing the steroid profile in doping control analysis. J Mass Spectrom 43: 877-891, 2008.

MATYSIK S, SCHMITZ G: Determination of steroid hormones in human plasma by GC-triple quadrupole MS. Steroids 99: 151-154, 2015.

MENG LJ, REYES H, AXELSON M, PALMA J, HERNANDEZ I, RIBALTA J, SJOVALL J: Progesterone metabolites and bile acids in serum of patients with intrahepatic cholestasis of pregnancy: effect of ursodeoxycholic acid therapy. Hepatology 26: 1573-1579, 1997.

MOON JY, JUNG HJ, MOON MH, CHUNG BC, CHOI MH: Heat-map visualization of gas chromatography-mass spectrometry based quantitative signatures on steroid metabolism. J Am Soc Mass Spectrom 20: 1626-1637, 2009.

MOON JY, CHOI MH, KIM J: Metabolic profiling of cholesterol and sex steroid hormones to monitor urological diseases. Endocr Relat Cancer 23: R455-R467, 2016.

NILSSON ME, VANDENPUT L, TIVESTEN A, NORLEN AK, LAGERQUIST MK, WINDAHL SH, BORJESSON AE, FARMAN HH, POUTANEN M, BENRICK A, MALIQUEO M, STENER-VICTORIN E, RYBERG H, OHLSSON C: Measurement of a comprehensive sex steroid profile in rodent serum by high-sensitive gas chromatography-tandem mass spectrometry. Endocrinology 156: 2492-2502, 2015.

PARIZEK A, HILL M, DUSKOVA M, VITEK L, VELIKOVA M, KANCHEVA R, SIMJAK P, KOUCKY M, KOKRDOVA Z, ADAMCOVA K, CERNY A, HAJEK Z, STARKA L: A comprehensive evaluation of steroid metabolism in women with intrahepatic cholestasis of pregnancy. PLoS One 11: e0159203, 2016.

PASKOVA A, PARIZEK A, HILL M, VELIKOVA M, KUBATOVA J, DUSKOVA M, ADAMCOVA K, KOUCKY M, SIMJAK P, CERNY A, STARKA L: Steroid metabolome in the umbilical cord: is it necessary to differentiate between arterial and venous blood? Physiol Res 63: 115-126, 2014.

POSPISILOVA H, VANKOVA M, HILL M, MELOUN M, BENDLOVA B, DUSKOVA M, STARKA L: The differences between aromatizable and non-aromatizable androgens in relation to body composition and metabolic syndrome risk factors in men. J Steroid Biochem Mol Biol 132: 105-111, 2012.

RARO M, PORTOLES T, PITARCH E, SANCHO JV, HERNANDEZ F, GARROSTAS L, MARCOS J, VENTURA R, SEGURA J, POZO OJ: Potential of atmospheric pressure chemical ionization source in gas chromatography tandem mass spectrometry for the screening of urinary exogenous androgenic anabolic steroids. Anal Chim Acta 906: 128-138, 2016.

ROSSI SA, JOHNSON JV, YOST RA: Short-column gas chromatography/tandem mass spectrometry for the detection of underivatized anabolic steroids in urine. Biol Mass Spectrom 23: 131-139, 1994.

SANCHEZ-GUIJO A, OJI V, HARTMANN MF, TRAUPE H, WUDY SA: Simultaneous quantification of cholesterol sulfate, androgen sulfates, and progestagen sulfates in human serum by LC-MS/MS. J Lipid Res 56: 1843-1851, 2015.

SHACKLETON C, MARCOS J, ARLT W, HAUFFA BP: Prenatal diagnosis of P450 oxidoreductase deficiency (ORD): a disorder causing low pregnancy estriol, maternal and fetal virilization, and the Antley-Bixler syndrome phenotype. Am J Med Genet A 129A: 105-112, 2004.

SHEN M, XIANG P, SHEN B, WANG M: Determination of endogenous anabolic steroids in hair using gas chromatography-tandem mass spectrometry (in Chinese). Se Pu 26: 454-459, 2008.

SOLDIN SJ, SOLDIN OP: Steroid hormone analysis by tandem mass spectrometry. Clin Chem 55: 1061-1066, 2009.

SOSVOROVA L, HILL M, MOHAPL M, VITKU J, HAMPL R: Steroid hormones in prediction of normal pressure hydrocephalus. J Steroid Biochem Mol Biol 152: 124-132, 2015.

STERZL I, HILL M, STARKA L, VELIKOVA M, KANCEVA R, JEMELKOVA J, CZERNEKOVA L, KOSZTYU P, ZADRAZIL J, MATOUSOVIC K, VONDRAK K, RASKA M: Patients with IgA nephropathy have altered levels of immunomodulatory $\mathrm{C} 19$ steroids. Glucocorticoid therapy with addition of adrenal androgens may be the choice. Physiol Res 66 (Suppl 3): S433-S442, 2017.

STYRISHAVE B, PEDERSEN KE, CLARKE O, HANSEN M, BJORKLUND E, SONNE C, DIETZ R: Steroid hormones in multiple tissues of East Greenland polar bears (Ursus maritimus). Polar Biol 70: 37-49, 2017. 
TOKUSHIGE K, HASHIMOTO E, KODAMA K, TOBARI M, MATSUSHITA N, KOGISO T, TANIAI M, TORII N, SHIRATORI K, NISHIZAKI Y, OHGA T, OHASHI Y, SATO T: Serum metabolomic profile and potential biomarkers for severity of fibrosis in nonalcoholic fatty liver disease. J Gastroenterol 48: 1392-1400, 2013.

TRINH T, HARDEN NB, COLEMAN HM, KHAN SJ: Simultaneous determination of estrogenic and androgenic hormones in water by isotope dilution gas chromatography-tandem mass spectrometry. J Chromatogr A 1218: 1668-1676, 2011.

VAN VYNCHT G, GASPAR P, DEPAUW E, MAGHUIN-ROGISTER G: Multi-residue screening and confirmatory analysis of anabolic steroids in urine by gas chromatography coupled with tandem mass spectrometry. J Chromatogr A 683: 67-74, 1994.

VANKOVA M, HILL M, VELIKOVA M, VCELAK J, VACINOVA G, DVORAKOVA K, LUKASOVA P, VEJRAZKOVA D, RUSINA R, HOLMEROVA I, JAROLIMOVA E, VANKOVA H, KANCHEVA R, BENDLOVA B, STARKA L: Preliminary evidence of altered steroidogenesis in women with Alzheimer's disease: Have the patients "OLDER" adrenal zona reticularis? J Steroid Biochem Mol Biol 158: 157-177, 2016.

VILJANTO M, PITA CH, SCARTH J, WALKER CJ, KICMAN AT, PARKIN MC: Important considerations for the utilisation of methanolysis in steroid analysis. Drug Test Anal 10: 1469-1473, 2018.

VITKU J, HERACEK J, SOSVOROVA L, HAMPL R, CHLUPACOVA T, HILL M, SOBOTKA V, BICIKOVA M, STARKA L: Associations of bisphenol $A$ and polychlorinated biphenyls with spermatogenesis and steroidogenesis in two biological fluids from men attending an infertility clinic. Environ Int 89-90: 166-173, 2016.

WONG AS, LEUNG GN, LEUNG DK, WAN TS: Doping control analysis of anabolic steroids in equine urine by gas chromatography-tandem mass spectrometry. Drug Test Anal 9: 1320-1327, 2017.

YAMADA M, ARAMAKI S, KUROSAWA M, KIJIMA-SUDA I, SAITO K, NAKAZAWA H: Simultaneous doping analysis of main urinary metabolites of anabolic steroids in horse by ion-trap gas chromatography-tandem mass spectrometry. Anal Sci 24: 1199-1204, 2008.

ZUEHLKE S, DUENNBIER U, HEBERER T: Determination of estrogenic steroids in surface water and wastewater by liquid chromatography-electrospray tandem mass spectrometry. J Sep Sci 28: 52-58, 2005. 